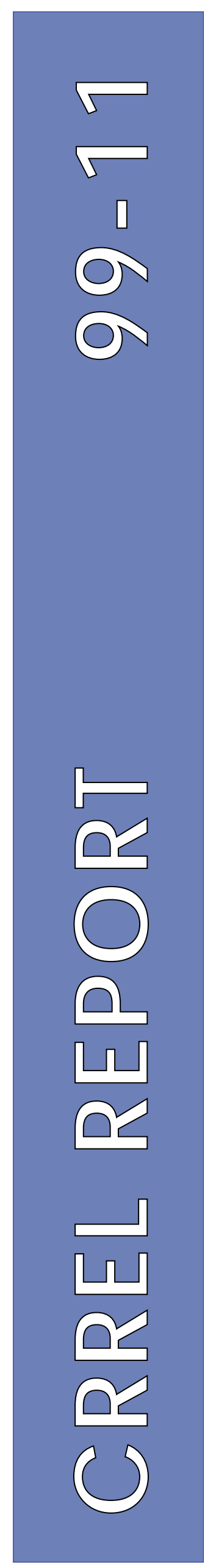

\title{
Hydraulic and Physical Properties Affecting Ice Jams
}

\author{
Kathleen D. White
}

December 1999

\section{US Army Corps of Engineers ${ }_{\circledast}$}

Cold Regions Research \& Engineering Laboratory 
Abstract: Hydraulic modeling of ice jams can be used to predict jam location, stages, thickness, and other characteristics. Knowledge of the range and variability of hydraulics and physical properties affecting ice jams is necessary to reduce the uncertainty associated with such modeling. This report provides an overview of the processes involved in ice jam hydraulics and discusses properties important in these processes.

Cover: March 1999 ice jam on the First Branch White River, Tunbridge, Vermont.

\section{How to get copies of CRREL technical publications:}

Department of Defense personnel and contractors may order reports through the Defense Technical Information Center:

DTIC-BR SUITE 0944

8725 J OHN J KINGMAN RD

FT BELVOIR VA 22060-6218

Telephone 18002253842

E-mail help@dtic.mil msorders@dtic.mil

WWW http://www.dtic.dla.mil/

All others may order reports through the National Technical Information Service: NTIS

5285 PORT ROYAL RD

SPRINGFIELD VA 22161

Telephone 18005536847 or 17036056000

17034874639 (TDD for the hearing-impaired)

E-mail_orders@ntis.fedworld.gov

WWW http://www.ntis.gov

A complete list of all CRREL technical publications is available from: USACRREL (CECRL-IB)

72 LYME RD

HANOVER NH 03755-1290

Telephone 16036464338

E-mail techpubs@crrel.usace.army.mil

For information on all aspects of the Cold Regions Research and Engineering Laboratory, visit our World Wide Web site: http://www.crrel.usace.army.mil 


\section{CRREL Report 99-11}

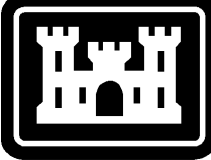

US Army Corps

of Engineers ${ }_{\circledast}$

Cold Regions Research \&

Engineering Laboratory

\section{Hydraulic and Physical \\ Properties Affecting Ice J ams}

Kathleen D. White

December 1999 


\section{PREFACE}

This report was prepared by Kathleen D. White, Research Hydraulic Engineer, Ice Engineering Research Division (IERD), U.S. Army Cold Regions Research and Engineering Laboratory (CRREL), Engineer Research and Development Center (ERDC), Hanover, New Hampshire.

This work was funded under the U.S. Army Corps of Engineers Civil Works Cold Regions Engineering Program Work Unit No. 33134, Hydraulic Properties of Ice Jams.

Technical reviews were provided by Dr. J.-C. Tatinclaux, Chief, IERD, and by Steven F. Daly, Research Hydraulic Engineer, IERD.

This publication reflects the personal views of the author and does not suggest or reflect the policy, practices, programs, or doctrine of the U.S. Army or government of the United States. The contents of this report are not to be used for advertising or promotional purposes. Citation of brand names does not constitute an official endorsement or approval of the use of such commercial products. 


\section{CONTENTS}

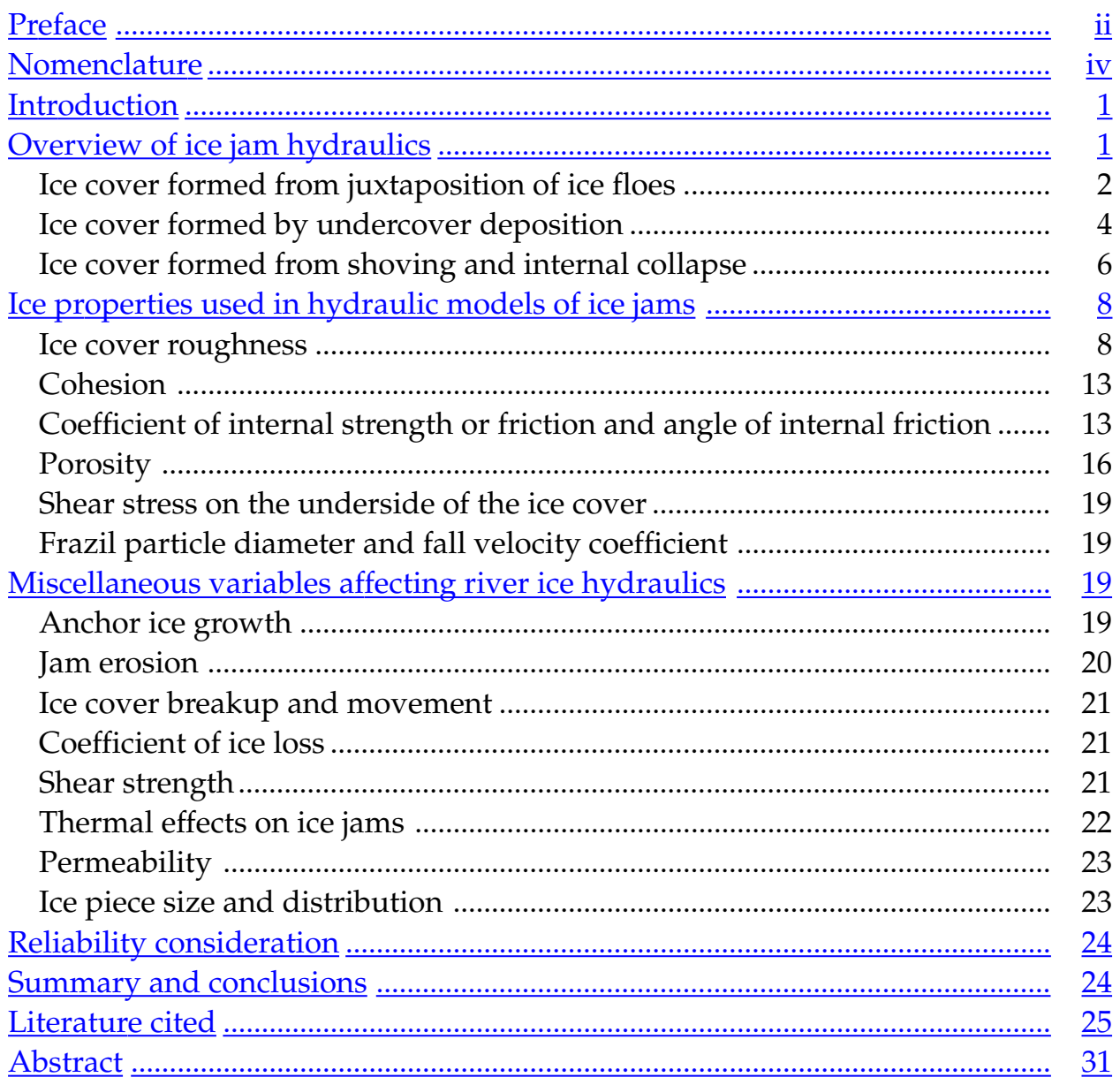

\section{ILLUSTRATIONS}

Figure

1. Typical juxtaposed ice cover, formed here from large broken pieces of sheet ice .............................................................................................. 2

2. Definition sketch for ice block stability …………...........................................

3. Frazil deposit formation ............................................................................. 5

4. Typical breakup ice jam with equilibrium section ........................................... 7

5. Variables important in flow beneath an ice cover ............................................ 8

6. Reported values of ice roughness .............................................................. 10

7. Nezhikhovskiy's suggested coefficients of ice roughness at the time of initial ice cover formation, based on the thickness and type of the parent ice material .................................................................................................. 10

8. Distribution of actual and simulated Manning's $n$ values ........................... 12

9. Calculated values of the coefficient of internal strength ................................ 14

10. Reported values of the angle of internal friction, $\phi$, for freshwater ice ........ 15

11. Relationship between angle of internal friction, $\phi$, and passive pressure

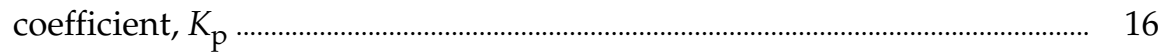

12. Reported porosity measurements and estimates ......................................... 17 
Figure

13. Porosity measurements of frazil deposits formed on trashracks in the CRREL refrigerated flume .................................................................. 18

14. Anchor ice growth characteristics at different flow velocities and flow depths

15. Distribution of ice piece sizes observed on the south channel of the St. Clair River, 25 February 1987

\section{TABLES}

Table

1. Values of ice roughness coefficient and composite roughness coefficient calculated from discharge measurements

2. Values of the coefficient of internal strength calculated by various researchers 13

3. Reported values of the angle of internal friction for freshwater ice 15

4. Reported measured or estimated values of porosity

5. Representative coefficients of variation based on data from Harr 1987 and some of the ice properties discussed in text.

6. Recommended values of hydraulic and physical properties affecting ice jams 


\section{NOMENCLATURE}

$\phi \quad$ Angle of internal friction

$\Phi \quad$ Dimensionless ice transport capacity

$\Phi_{\mathrm{n}} \quad$ Dimensionless ice transport capacity modified to reflect particle shape

$\eta \quad$ Ice thickness

$\eta_{\mathrm{t}} \quad$ Ice thickness after thinning by erosion

$\lambda$ or $k_{1} \quad$ Lateral stress coefficient, close to 1 for breakup ice jams

$\lambda \quad$ Seepage coefficient for porous flow

$\mu \quad$ Coefficient describing the internal strength of the ice cover, $=k_{0} K_{\mathrm{p}} \lambda(1-p)$

$\Theta \quad$ Dimensionless flow strength

$\Theta_{\mathrm{C}} \quad$ Critical dimensionless flow strength, $\approx 0.041$

$\Theta_{\mathrm{n}} \quad$ Dimensionless flow strength modified to reflect particle shape

$\rho \quad$ Density of water

$\rho_{i} \quad$ Density of ice

$\tau \quad$ Shear force on the underside of the ice cover

$\tau_{\mathrm{b}} \quad$ Shear resistance provided by the river banks

$\xi \quad$ Coefficient used to determine thickness of the theoretical flow separation zone at the upstream edge of the ice cover

$B \quad$ River width

c Coefficient used in determining under-ice depth (1.5875 in SI units of $\mathrm{s} / \mathrm{m}^{1 / 3}$ and 1.0654 in English units of $\mathrm{s} / \mathrm{ft}^{1 / 3}$ )

$c_{1} \quad$ Ice loss coefficient

$\mathrm{C}_{\mathrm{i}} \quad$ Cohesion

$\mathrm{C}_{\mathrm{f}} \quad$ Fall velocity coefficient

d Length scale used in Froude number, or frazil particle diameter

$d_{\mathrm{n}} \quad$ Nominal particle diameter

$d_{\mathrm{s}} \quad$ Variable describing the particles in an ice accumulation, $=6 / M_{\mathrm{s}}$

$D \quad$ Density of the ice accumulation

$F \quad$ Froude number

FI Six-hour freezing index

$g \quad$ Gravity

$h \quad$ Water surface elevation in the equilibrium section of jam

$H \quad$ Upstream water depth

$k_{\mathrm{i}} \quad$ Thermal conductivity of ice

$k_{0} \quad$ Coefficient of friction, $=\tan \phi$

$K \quad$ Dimensionless seepage coefficient

$K_{\mathrm{p}}$ or $k_{\mathrm{x}} \quad$ Passive pressure coefficient, $=\tan ^{2}\left[45^{\circ}+\frac{\phi}{2}\right]$

$L \quad$ Ice block length

$L_{\mathrm{f}} \quad$ Latent heat of fusion of water

$M_{\mathrm{s}} \quad$ Specific area per unit volume of the solid particles in an accumulation

$n_{\mathrm{b}} \quad$ Manning's $n$ for the bed

$n_{\mathrm{c}} \quad$ Composite Manning's $n$ for the channel

$n_{\mathrm{i}} \quad$ Manning's $n$ for the underside of the ice

$p \quad$ Porosity of the ice accumulation

$q \quad$ Discharge per unit width

Q Discharge

$R_{\mathrm{i}} \quad$ Hydraulic radius of the ice-covered channel, $\approx y_{\mathrm{i}} / 2$

$s_{\mathrm{i}} \quad$ Specific gravity of ice, $=\rho_{\mathrm{i}} / \rho$ 


$\begin{array}{ll}S_{\mathrm{f}} & \text { Water slope } \\ t & \text { Ice block thickness } \\ t^{\prime} & \text { Ice block freeboard } \\ T_{\mathrm{a}} & \text { Air temperature } \\ T_{\mathrm{i}} & \text { Ice temperature } \\ u_{*} & \text { Shear velocity, }=\sqrt{g R_{\mathrm{i}} S_{\mathrm{f}}} \\ v & \text { Average velocity at the upstream edge of the ice cover } \\ v_{\mathrm{i}} & \text { Average velocity below the ice cover } \\ v_{\mathrm{e}} & \text { Critical erosion velocity } \\ V_{\mathrm{j}} & \text { Volume of ice in the jam } \\ V_{\mathrm{t}} & \text { Total volume of the jam } \\ V v & \text { Volume of voids } \\ x & \text { Distance } \\ y_{\mathrm{i}} & \text { Under-ice depth }\end{array}$




\title{
Hydraulic and Physical Properties Affecting Ice Jams
}

\author{
KATHLEEN D. WHITE
}

\section{INTRODUCTION}

River ice jams can form suddenly, bringing about rapid fluctuations in stage. Ice jams can cause flooding upstream and decrease downstream discharge. Damage to riverine structures such as bridges, locks, dams, dikes, groins, levees, and riprap installations is also possible. Ice jams affect navigation through delays, stoppages, or damage to tows, barges, and mooring/fleeting areas. Ice can block hydropower and water supply intakes. Ice-induced scour may cause the erosion of river beds and banks, with adverse impacts on fish and wildlife habitat, as well as the exposure of utilities buried beneath the streambed. Emergency and medical relief to flooded areas may be limited by flooding or ice-related scour and erosion of roads resulting in road closures, or by the closure of bridges weakened or destroyed by ice. The potential exists for death or serious injury during ice-related flooding, evacuations, and other ice mitigation operations.

Ice-related damages can be minimized or avoided through the use of hydraulic modeling to predict jam location, upstream and downstream stages, jam thickness, and other jam characteristics. While knowledge about ice jam formation, progression, and failure has increased in recent years, to date no deterministic model of these ice jam processes has been developed. In part, these complex physical processes are poorly understood because field observations of ice processes and properties are spatially and temporally limited and can be dangerous to acquire. Data are often scattered, and although earlier literature reviews (e.g., Bolsenga 1968) contain a great deal of historical information regarding river ice covers, they do not include the tremendous amount of information gathered over the past few decades. As a result, many of the variables and parameters included in the empirical, analytical, and numerical models that do exist for some ice jam processes are not sufficiently well known or described.

Beltaos (1995) and Ashton (1986) provide thorough discussions of the various processes important in ice cover initiation, growth, breakup, transport, and jamming. The purpose of the present study is to review available information on the properties of ice covers and ice jams that are important in modeling river ice jam hydraulics. An overview of ice jam hydraulics identifies specific ice properties of interest, which are discussed in detail in the following section. Information is also presented about miscellaneous ice properties addressed in the literature but not explicitly included in hydraulic models of ice jams.

\section{OVERVIEW OF ICE JAM HYDRAULICS}

Formation processes of river ice covers range from the purely static to the purely dynamic. Static ice cover formation is a largely thermal process in that the initiation and growth of ice crystals result from heat transfer between the water and the atmosphere. Statically initiated ice covers in rivers are found in quiescent areas and along the banks (border ice). Dynamic ice cover formation results from the mechanical processes associated with floe interactions. These may range from relatively lowenergy processes such as the juxtaposition of ice floes into a single layer of ice that then freezes in place, or higher-energy processes such as the accumulation of floes into an ice jam by shoving and internal collapse. Temperature plays an important role in ice cover formation. Andres (1999) states that for large, moderately sloping rivers, colder temperatures will result in juxtaposition, while higher temperatures will result in ice covers formed by shoving and internal collapse (or "consolidation"). However, he finds that for very mild slopes and very steep slopes, the process is rela- 
tively independent of temperature: if the river slope is mild, juxtaposed ice covers form, and if the slope is steep, the ice cover will form from shoving. Once formed, ice covers can also thicken via thermal processes, by flooding and refreezing of the surface, or by transport and deposition of ice beneath the cover. An overview of the processes resulting in the formation of ice covers and ice jams is presented below.

\section{Ice cover formed from juxtaposition of ice floes}

Juxtaposition occurs when frazil or solid ice floes carried downstream reach an obstacle (such as an ice cover) and stop, forming a single layer ice cover (Fig. 1). Freezeup accumulation and progression due to juxtaposition can be quite rapid. For example, Gerard and Andres (1982) noted rates of up to $7 \mathrm{~km} /$ day for a freezeup jam on the North Saskatchewan River, Alberta, while Beltaos (1983) reported $8.4 \mathrm{~km} /$ day over a 20 -hour period on the Thames River, New Brunswick. The physical process of the juxtaposition of frazil or solid ice floes into a single layer ice cover has not yet been carefully described, perhaps because these ice accumulations are less threatening than thickened jams. Yet, juxtaposition is often the primary progression mode for initial ice cover formation in large rivers and for freezeup jams. Traditionally, two approaches have been taken in determining whether the incoming ice floes will be stable and juxtaposition is possible: use of a surface velocity criterion or of a criterion describing the rotational stability of the incoming ice floes.
The critical velocity would be the maximum velocity at which juxtaposition can still occur; higher velocities would result in underturning of ice floes or shoving. Majewski and Grzes (1986), for example, reported that velocities less than about 0.5 to $0.7 \mathrm{~m} / \mathrm{s}$ allowed juxtaposition in one reach of the Vistula River, Poland, while greater than 0.6 to $0.7 \mathrm{~m} / \mathrm{s}$ caused shoving. The idea of a critical velocity criterion is attractive, yet it fails to account for many of the important variables, such as ice discharge, and the thickness, size, and cohesion of the ice floe. As a result, a surface velocity criterion is not acceptable except in limited, sitespecific cases.

Efforts to expand the critical surface criterion led to variations on the Froude number (e.g., Pariset and Hausser 1961, Pariset et al. 1966). The Froude number, $F$, is the ratio of inertial forces to gravity forces:

$$
F=\frac{v}{\sqrt{g d}}
$$

where $v$ is the average velocity upstream from the ice cover, $g$ is gravity $\left(981 \mathrm{~cm} / \mathrm{s}^{2}\right)$, and $d$ is some appropriate length scale, generally taken to be the upstream flow depth, $H$, for open-water situations. A more appropriate length scale when considering ice transport would be the ice piece thickness. For ease in application, a juxtaposition criterion based on $F$ is often presented in the form of a velocity criterion. Pariset and Hausser (1961) presented their Froude criterion in the form of a critical velocity, but as they observed, ice covers have

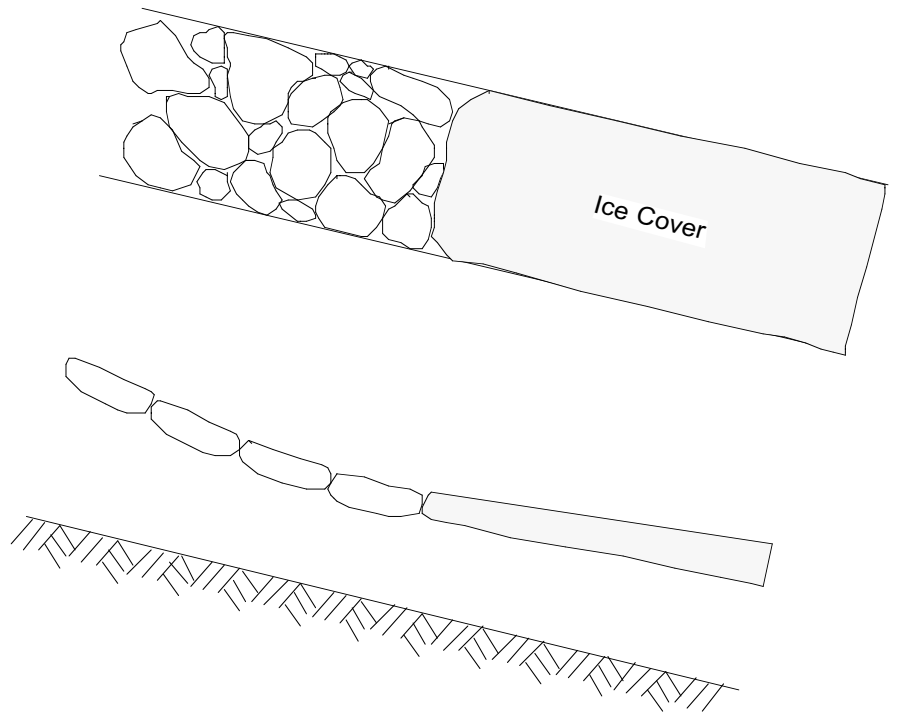

Figure 1. Typical juxtaposed ice cover, formed here from large broken pieces of sheet ice. 
been known to progress by juxtaposition at velocities more than three times greater than the critical velocity they predicted. Using a different approach, Tremblay and Thibeault (1980) proposed a critical velocity criterion for the Milles Iles River (Quebec) based on the Chezy formula that included floe size and ice discharge.

Later researchers (e.g., Uzuner and Kennedy 1972, 1974; Ashton 1974; Uzuner 1975; Michel 1978; Tatinclaux and Gogus 1981) used both laboratory experiments and analysis to arrive at a rational Froude number to describe the limits of the rotational stability of the ice floes. Generally, a densimetric Froude number was used, with a length scale based on some ratio between the ice block thickness and water depth, modified by the difference in the densities of water, $\rho$, and ice, $\rho_{i}$. Ashton (1974) successfully described the experimental data using an analysis based on the "nospill" condition, which postulates that the limit of rotational stability occurs when the upper, upstream corner of the block becomes submerged. He assumed that the underturning moment was caused by the acceleration of flow under the block because of the constriction caused by the block. Despite the obvious problem that the constriction of flow would be negligible in deep water, Ashton's criterion was widely adopted.

Daly and Axelson (1990) demonstrated that floating blocks have a well-defined maximum righting moment. They noted that the limit of rotational stability has been reached when the underturning moments exceed this maximum and a no-spill condition was not necessary. They developed an analytical expression for the limit of rotational stability in terms of the hydrostatic righting moment of the block, expressed in the form of a densimetric Froude number. Their work was incorporated by McGilvary and Coutermarsh (1992) in a dynamic analysis of ice block stability based on careful measurements of the pressure distributions around the leading edge and underside of a model ice floe for various flow depths (Coutermarsh and McGilvary 1991, 1993). This pressure distribution, produced by the acceleration of the flow as it passed under the block, creates an underturning moment acting on the block that could cause underturning in both deep and shallow water.

McGilvary and Coutermarsh (1992) further extended the analysis by including the angular momentum of the block, and demonstrated that the angular momentum could be an important factor in causing blocks to underturn (all of the previous analyses had been static in that they neglected the angular momentum of the rotating blocks). They found that the Froude criteria of Pariset and Hausser (1961) and Ashton (1974) underpredicted the critical Froude number for stability, particularly for small ratios of floe thickness to depth. They did find good agreement, however, with the shallow water criterion for stability presented by Daly (1984):

$$
F=\frac{v}{\sqrt{g t_{\mathrm{b}}}} \leq \frac{(\sqrt{4 / 3})\left(1-\frac{t_{\mathrm{s}}}{H}\right) \beta}{\sqrt{1-\left(1-\frac{t_{\mathrm{s}}}{H}\right)^{2}-\left(\frac{t_{\mathrm{b}}}{H}\right)\left(\frac{t_{\mathrm{b}}}{L}\right)^{2}\left(\frac{\rho_{\mathrm{i}}}{\rho}\right)^{3}}}
$$

where $t_{\mathrm{b}}$ is ice block thickness, $L$ is ice block length, $H$ is upstream water depth, and $\beta$ is a coefficient that is independent of underturning velocity, and block length, thickness, and density, determined to be equal to 0.262 . A definition sketch is given in Figure 2. The submerged depth of the ice block, $t_{\mathrm{s}}$ is calculated using

$$
t_{\mathrm{s}}=\left(\frac{\rho_{\mathrm{i}}}{\rho}\right) t_{\mathrm{b}}
$$

Daly (1984) noted that this equation, developed as a simple curve fit to data from Uzuner and Kennedy (1972), Ashton (1974), and Larsen (1975), is not strictly applicable to deep water (ice block thickness-to-depth ratios less than about 0.1).

More recently, Andres (1999) has proposed the use of a dimensionless stability number to determine whether juxtaposition or shoving will dominate the ice cover formation process under different hydrologic and meteorological conditions. His analysis includes the effects of temperature in the form of air temperature $\left(T_{\mathrm{a}}\right)$, the thermal conductivity of the ice $\left(k_{\mathrm{i}}\right)$, and the latent heat of fusion of the water $\left(L_{\mathrm{f}}\right)$. The dimensionless stability number takes the form

$$
X=\frac{T_{\mathrm{a}} B k_{\mathrm{i}}}{Q S_{\mathrm{f}} \rho_{\mathrm{i}} L_{\mathrm{f}}}
$$

where $Q$ is discharge, $B$ is river width, and $S_{\mathrm{f}}$ is the water slope. A typical value of the latent heat of fusion of water is $334 \mathrm{~J} / \mathrm{g}$ (Batchelor 1967). The thermal conductivity of the ice is related to temperature by the following equation (USACE 1999): 


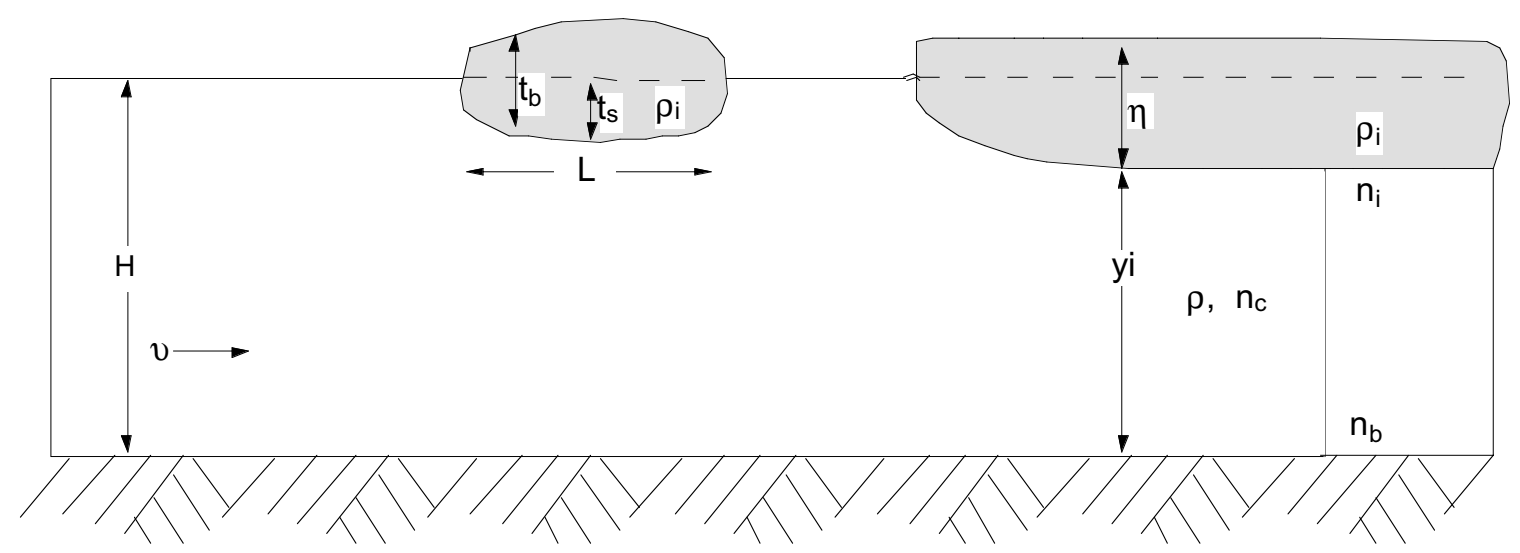

Figure 2. Definition sketch for ice block stability.

$$
k_{\mathrm{i}}=2.21-0.11 T_{\mathrm{i}}
$$

where $T_{\mathrm{i}}$ is the temperature of the ice $\left({ }^{\circ} \mathrm{C}\right)$ and $k_{\mathrm{i}}$ has units $\mathrm{J} / \mathrm{m} \mathrm{s}^{\circ} \mathrm{C}$. Andres reported that the critical dimensionless stability number separating juxtaposition and shoving on the Peace River in northern Alberta is about 0.0003 , with shoving more often observed at lower values and juxtaposition most often observed at higher values. He noted that river slope and crushing strength of the ice (again, related to temperature) contributed to the uncertainty in determining the critical dimensionless stability number. Although not widely tested at this time, this method holds promise for determining juxtaposition potential for ice cover formation and freezeup jams.

HEC-RAS assumes single-layer juxtaposition of floes if the ice-jam force balance (see section on shoving and internal collapse below) shows that the thickness of the parent ice cover making up the floes exceeds that necessary to balance forces in the downstream direction. The ICETHK option of the USACE step-backwater computer program HEC-2 (USACE 1990) uses the criteria developed by Ashton (1974) and Michel (1978) to determine when juxtaposition may occur. However, it is recommended here that eq 2 be applied to variables derived from ICETHK and other numerical models for the determination of juxtaposition potential because of its good agreement with the results of the fairly complex model presented by McGilvary and Coutermarsh (1992). Application of eq 2 will require some knowledge or estimation of the following ice properties: $t_{\mathrm{b}}, \rho, \rho_{\mathrm{i}}$, and $H$, of which two, $\rho$ and $\rho_{\mathrm{i}}$, are well known (1000 $\mathrm{kg} / \mathrm{m}^{3}$ and $916 \mathrm{~kg} / \mathrm{m}^{3}$, respectively).

\section{Ice cover formed by undercover deposition}

Undercover deposition of ice occurs when incoming frazil or solid ice floes are unstable at the upstream end of an ice cover (e.g., juxtaposition criterion is exceeded). Once the floes underturn, they can be transported beneath the ice cover and into the open water beyond, or they may deposit beneath the ice, depending on the river hydraulics and the ice properties (Fig. 3). Predictions of where and how much under-ice deposition will occur have been made using three approaches: critical velocity; Froude-number-based block stability criteria similar to those discussed above, but for submerged ice floes; and, more recently, application of bed-load transport theory. Ice jam thickening by deposition of ice is not specified in either HEC-RAS or ICETHK, although ICETHK does allow thinning of an ice cover by erosion when the critical velocity is exceeded.

The critical deposition velocity approach assumes that frazil deposits (or hanging dams) accumulate from upstream to downstream, beginning with the most upstream location where the average cross-sectional flow velocity is less than some critical deposition velocity. Frazil will deposit at that location until the critical velocity has been reached. Any additional frazil will be transported downstream to some point where the velocity is less than the critical velocity, where the process begins again. According to Beltaos (1995), this critical velocity method is used in the numerical model ICESIM to estimate the location and thickness of frazil deposition.

Observations reported by Michel and Drouin (1981) indicate that critical velocity can vary over the course of a winter. They reported that the value 


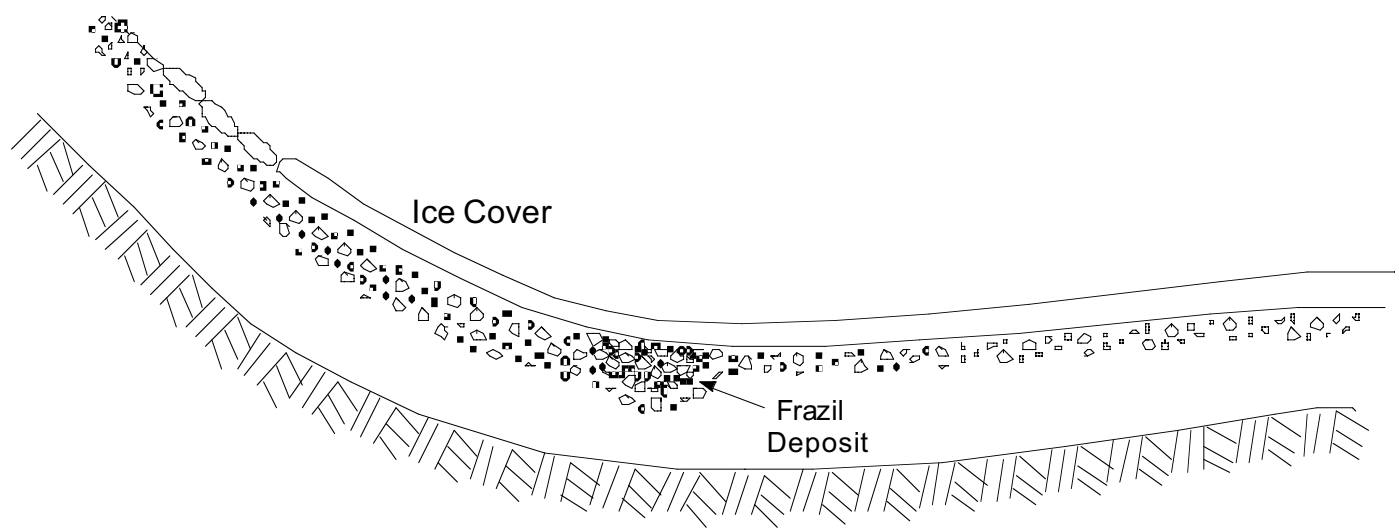

Figure 3. Frazil deposit formation.

decreased from $0.9 \mathrm{~m} / \mathrm{s}$ in early winter to $0.6 \mathrm{~m} / \mathrm{s}$ in late winter on the LaGrande River, Quebec. Daly (1994) attributes reported variations in critical velocity to factors such as the form of the frazil, the length of travel, and the degree of supercooling in the river. Michel (1984) suggests that variations in critical velocity may be explained by the physical state of the frazil particles. In his experience, critical velocities decrease with age from a high of about $1.4 \mathrm{~m} / \mathrm{s}$ for active, or recently formed, frazil to a low of about $0.6 \mathrm{~m} / \mathrm{s}$ for aged frazil floes.

These variations, along with variations in the critical velocity between rivers and between different reaches on the same river, made it difficult to apply this method. In view of these difficulties, Sun and Shen (1988) proposed an empirical method to estimate ice thickness based on Froude number, similar to the approach taken for juxtaposition. The stability criteria resulting from laboratory studies and analytical analyses (e.g., Ashton 1974, Gogus and Tatinclaux 1981, Daly and Axelson 1990) have taken the form of some variation on the densimetric Froude number. However, Starosolzky (1981) suggested that scatter in experimental data for parallelepipeds using this method could be explained by a bed-load transport approach.

Although not yet applied to blocks, bed load transport has been applied to frazil ice by Shen and Wang (1992), who proposed a new method to analyze frazil transport based on the concept that the movement of the ice particles is caused by the shear stress acting on the particles. Essentially, the method relies on the functional relationship between the dimensionless ice transport capacity, $\Phi$, and the dimensionless flow strength, $\Theta$ :

$$
\Phi=f(\Theta) .
$$

The dimensionless ice transport capacity is described by

$$
\Phi=\frac{q_{\mathrm{i}}}{\sqrt{\frac{\rho-\rho_{\mathrm{i}}}{\rho} g d^{3}}}
$$

in which $q_{\mathrm{i}}$ is the ice transport capacity per unit width and $d$ is the particle diameter. The dimensionless flow strength is calculated using

$$
\Theta=\frac{\tau}{\left(\rho-\rho_{\mathrm{i}}\right) g d}
$$

where $\tau$ is the shear force on the underside of the ice cover. Laboratory studies reported by Shen and Wang (1995) suggested that the dimensionless parameters $\Phi$ and $\Theta$ in eq 6 and 7 should be modified to account for the effect of the shape of the particles, resulting in the following formulations:

$$
\Phi_{\mathrm{n}}=\frac{q_{\mathrm{i}}}{C_{\mathrm{f}} \sqrt{\frac{\left(\rho-\rho_{\mathrm{i}}\right)}{\rho} g d_{\mathrm{n}}{ }^{3}}}
$$

and

$$
\Theta_{\mathrm{n}}=\frac{u_{*}^{2}}{C_{\mathrm{f}}^{2} g d_{\mathrm{n}} \frac{(\rho-\rho i)}{\rho}}
$$

where $C_{\mathrm{f}}$ is a fall velocity coefficient, $d_{\mathrm{n}}$ is the nominal particle diameter, and $u^{*}$ is the shear velocity:

$$
u_{*}=\sqrt{g R_{\mathrm{i}} S_{\mathrm{f}}}=\sqrt{\frac{\tau}{\rho}}
$$


where $R_{\mathrm{i}}$ is the hydraulic radius of the ice-covered channel, and $\tau$ is the shear stress on the underside of the ice cover.

Because the width of a river channel is often much wider than its depth, the open-water hydraulic radius $R$ (the ratio of cross-sectional area to wetted perimeter) of an open-water reach is often approximated as $H$, the water depth. In the ice-covered case, the wetted perimeter is effectively doubled, so $R_{\mathrm{i}}$ can be approximated by $y_{\mathrm{i}} /$ 2 , where $y_{\mathrm{i}}$ is the under-ice depth, often calculated from Manning's formula as

$$
y_{i}=\left[\frac{c q n_{\mathrm{c}}}{S_{\mathrm{f}}^{1 / 2}}\right]^{3 / 5}
$$

where $c$ is a coefficient $\left(1.5875 \mathrm{in}\right.$ SI units of $\mathrm{s} / \mathrm{m}^{1 / 3}$ and 1.0654 in English units of $\left.\mathrm{s} / \mathrm{ft}^{1 / 3}\right), q$ is the discharge per unit width, and $n_{\mathrm{c}}$ is the composite Manning's $n$ for the channel. Nezhikhovskiy (1964) reviewed methods of determining composite channel roughness and suggested the use of the Belokon-Sabaneev formula:

$$
n_{\mathrm{c}}=\left[\frac{n_{\mathrm{i}}^{3 / 2}+n_{\mathrm{b}}^{3 / 2}}{2}\right]^{2 / 3}
$$

in which $n_{\mathrm{i}}$ is the Manning's $n$ for underside of ice and $n_{\mathrm{b}}$ is the Manning's $n$ for the bed. Other formulations are presented in Uzuner (1975). The roughness ratio can be used to modify the iceaffected hydraulic radius as follows:

$$
R_{\mathrm{i}}=\left(\frac{n_{\mathrm{i}}}{n_{\mathrm{c}}}\right)^{3 / 2} \frac{y_{\mathrm{i}}}{2} \text {. }
$$

White and Acone (1998) modeled frazil deposition beneath an ice cover at a river-reservoir confluence utilizing both ICETHK and the simplified version of Shen and Wang's functional relationship in eq 6 to 10:

$$
\Phi_{\mathrm{n}}=5.487\left(\Theta_{\mathrm{n}}-\Theta_{\mathrm{c}}\right)^{1.5}
$$

where $\Theta_{c}=0.041$. The following process was used: 1) a hydraulic model with stable ice cover must be developed for the reach of river in question; 2) variables $R$ and $S_{\mathrm{f}}$ calculated by the hydraulic model are used to estimate $\Theta_{\mathrm{n}}$ using eq 10 and 11 , from which $\Phi_{\mathrm{n}}$ is calculated using eq 15 ; 3) frazil transport is assumed to occur at locations where a solution to eq 15 is obtained; if no solution is possible (i.e., $\Phi_{\mathrm{n}}<\Phi_{\mathrm{c}}$ ), deposition is assumed to occur. An iterative process is required to obtain an equilibrium frazil deposit. The ice cover of the hydraulic model is thickened at the locations where deposition is identified, beginning with the most upstream location. The ice-covered hydraulic model is rerun, providing new values of $R$ and $S_{\mathrm{f}}$, which are used to calculate a new $\Phi_{\mathrm{n}}$ for each cross section, thus identifying locations of transport and deposition under the updated hydraulic conditions. The process is repeated until no further deposition is possible or until the volume of the deposited frazil ice nears the estimated volume produced. The variables required in this method are $\rho, \rho_{\mathrm{i}}, d_{\mathrm{n}}, C_{\mathrm{f}}, S_{\mathrm{f}}$, and the variables necessary to calculate $R: q, n_{\mathrm{i}}, n_{\mathrm{b}}$, and $n_{\mathrm{c}}$.

\section{Ice cover formed from shoving and internal collapse}

When the forces exerted by incoming ice increase to the point that they exceed the internal strength of ice accumulations formed by juxtaposition or thickened by deposition, the ice accumulation will fail. The failure may be large scale, resulting in the transport of ice for large distances until the accumulation stops again, or it may be smaller in scale, resulting in a local shoving and thickening of the accumulation. The shoving and thickening process is an inherently unsteady process that may eventually cause the formation of what is often termed an equilibrium jam; that is, a jam in which a uniform section of ice has reached a thickness where the external and internal forces are in equilibrium (Fig. 4).

Zufelt and Ettema (1997) developed an unsteady model of the shoving and thickening process, and a stationary ice cover subroutine has been used in conjunction with the one-dimensional unsteady flow model UNET developed by the Hydrologic Engineering Center (HEC) (USACE 1995). The use of a dynamic ice cover in UNET is under development (McGilvary et al. 1995, Daly et al. 1997). However, most currently used models assume steady state conditions, including the HEC's River Analysis System (HEC-RAS) (USACE 1997), the ICETHK option of the USACE stepbackwater computer program HEC-2 (USACE 1990), and Canadian models RIVJAM and ICESIM (Healy et al. 1997). This assumption is actually conservative except in the downstream transition zone, and hence has been deemed acceptable. Zufelt (1999) presents a test that can be used to 

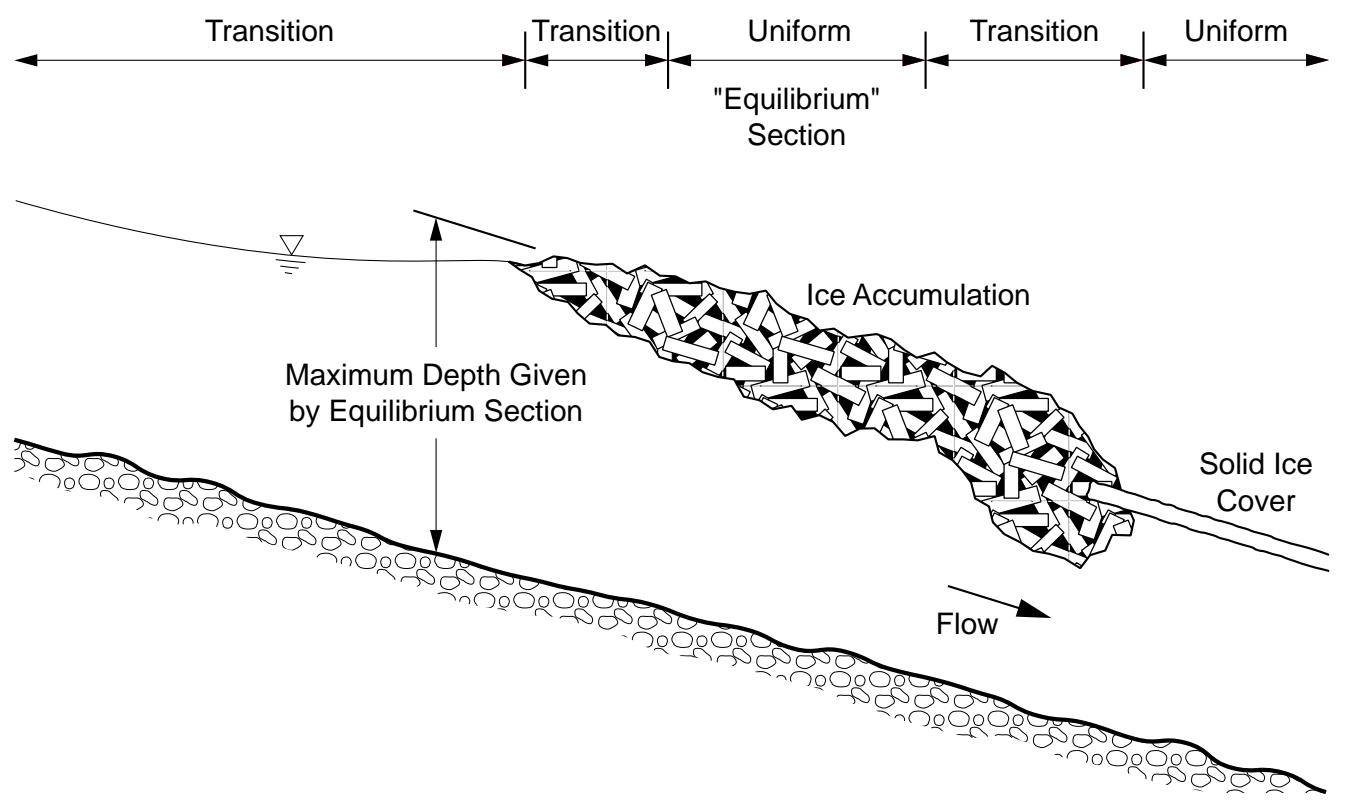

Figure 4. Typical breakup ice jam with equilibrium section.

determine when the assumption of steady state will be violated to a sufficient degree that unsteady methods should be utilized. Preliminary results indicate that the steady-state assumption is acceptable in many cases.

A number of expressions are available for calculating the equilibrium ice jam thickness in breakup ice jams, that is, the uniform thickness section of an ice jam that has formed through shoving of the ice (Pariset et al. 1966; Uzuner and Kennedy 1974; Beltaos 1978, 1995). The expression selected for use in HEC-RAS is based on the ice-jam force balance equation in which the stresses within the jam are balanced against the external stresses on the jam (USACE 1997, Daly et al. 1998):

$$
\frac{d\left(\overline{\sigma_{x}} \eta\right)}{d x}+\frac{2 \tau_{\mathrm{b}} \eta}{B}=\rho_{\mathrm{i}} g S_{\mathrm{f}} \eta+\tau
$$

where $\sigma_{\mathrm{x}}$ is the stress in the streamwise direction $x$ (assumed to be constant across the width of the channel, $B), \eta$ is the thickness of the ice accumulation, $\tau_{\mathrm{b}}$ is the shear resistance provided by the river banks, and $\tau$ is the shear stress on the underside of the jam. This force balance, expressed by Ashton (1986) in the form below, was used by Tuthill et al. (1998) in the ICETHK option of HEC-2:

$$
0=\mu g \rho_{\mathrm{i}}\left(1-\frac{\rho_{\mathrm{i}}}{\rho}\right) \eta^{2}-\left(g \rho_{\mathrm{i}} S_{\mathrm{f}}-2 C_{\mathrm{i}}\right) \eta-\tau B
$$

where $\mu$ is the coefficient of internal strength of the ice cover, sometimes called the friction coefficient, and $C_{i}$ is the cohesion. Cohesion is often neglected for breakup ice jams, but can be important for freezeup jams. The shear stress on the underside of the jam, $\tau$, can be expressed as

$$
\tau=\rho g R_{\mathrm{i}} S_{\mathrm{f}} .
$$

For negligible cohesion $\left(C_{\mathrm{i}}=0\right)$, eq 17 yields the following expression for the equilibrium ice jam thickness:

$$
\eta=\frac{B S_{\mathrm{f}}}{2 \mu\left(1-s_{\mathrm{i}}\right)}\left[1+\sqrt{1+\frac{4 \mu\left(1-s_{\mathrm{i}}\right) R_{\mathrm{i}}}{s_{\mathrm{i}} B S_{\mathrm{f}}}}\right]
$$

where $s_{\mathrm{i}}$ is specific gravity of ice $\left(\rho_{\mathrm{i}} / \rho\right)$. The water surface elevation in the equilibrium section of a breakup ice jam, $h$, is calculated by

$$
h=y_{\mathrm{i}}+s_{\mathrm{i}} \eta \text {. }
$$

In summary, application of equilibrium ice thickness models (e.g., eq 19) will require some knowledge or estimation of the following ice properties: $C_{\mathrm{i}}, \mu, \rho, \rho_{\mathrm{i}}, n_{\mathrm{b}}, n_{\mathrm{i}}, n_{\mathrm{c}^{\prime}} L$, and $H$, of which two, $\rho$ and $\rho_{i}$, are well known. 


\section{ICE PROPERTIES USED IN HYDRAULIC MODELS OF ICE JAMS}

The properties of ice jams included in the models cited above include ice cover roughness, cohesion, measures of internal strength such as internal friction angle and the angles of static and dynamic friction, the shear force on the ice cover and its shear strength, and frazil particle diameter and fall velocity. Each of these is addressed in a separate section below, followed by discussions of ice transport, thermal effects on ice jams, and miscellaneous hydraulic properties of ice jams such as porosity, anchor ice growth, jam erosion, ice cover breakup and movement, thermal effects, coefficient of ice loss, and permeability.

\section{Ice cover roughness $\left(n_{\mathrm{i}}\right)$}

Ice cover roughness is the most thoroughly explored hydraulic property of ice covers. In fact, the biennial River Ice Workshops sponsored by the Canadian government (see, e.g., Ismail 1997), began as a workshop on the hydraulic resistance of river ice in 1980 largely devoted to developing an understanding of ice cover roughness (Tsang and Beltaos 1980). Yet there is still a need to obtain reliable field measurements of ice jams roughness. A review of formulas for computing composite roughness coefficients as well as a discussion of roughness estimates made by others (Lotter 1932, 1941; Belokoń 1938, 1940; Panov 1960) is included in Nezhikhovskiy (1964). He suggests that many published values of $n_{\mathrm{i}}$ and $n_{\mathrm{c}}$ are incorrect due to errors in measured and estimated discharge and water slope. Also, the smoothing of the bottom surface of the ice over time and as the ice cover thickens-effects noted by many observers-can be a source of error in estimates of roughness, which is often taken as constant over time. Although it has been argued by some that excessive reliance is placed on this single work by Nezhikhovskiy, a careful review of this work indicates that both the method and the number of samples utilized by Nezhikhovskiy inspire confidence. Rather, it is the incorrect application of results clearly intended by Nezhikhovskiy for use during initial ice cover formation due to frazil or sheet ice accumulation or frazil deposition only, to other situations, particularly breakup jams, that engenders difficulty in roughness estimation.

Roughness is approached in several ways and using several coefficients. Roughness is almost always determined using a two-layer system, that is, dividing the flow area into separate layers affected by the bed and the ice cover (Fig. 5). A composite channel roughness coefficient is calculated through application of standard flow equations such as Manning's equation or the DarcyWeisbach equation (numerous researchers) or boundary-layer theory (e.g., Gogus and Tatinclaux 1981). Given an estimate of bed roughness, the roughness of the underside of the ice can then be calculated using a formula such as the BelokonSabaneev formula (eq 11). Roughness has also been calculated from estimates of the shear stress on the underside of the ice cover (e.g., Knowles and Hodgins 1980, Hara et al. 1997). Unfortunately, few data useful in calculating roughness exist, particularly for breakup jams. Also, the presence of an ice jam can cause changes in bed roughness, which

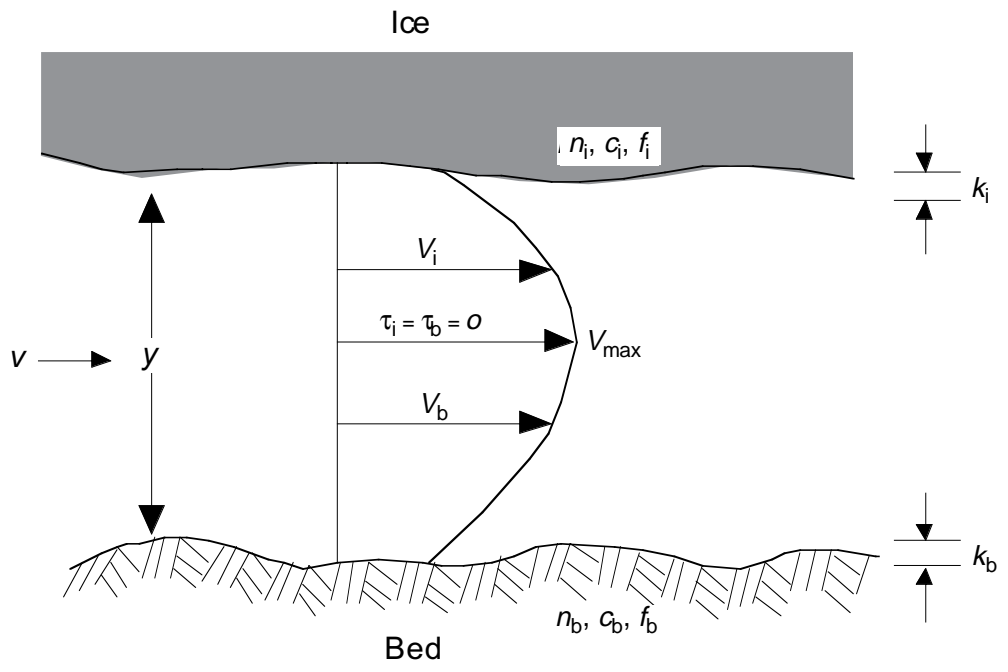

Figure 5. Variables important in flow beneath an ice cover. 
in turn affects the calculation of ice roughness. In practice, then, roughness is generally estimated during calibration of numerical models, where it essentially becomes a lumped variable representing other unknown jam components.

The most commonly used roughness coefficient is the Manning's $n$, followed by the Darcy friction factor $f$. The Chezy $C$ and the equivalent sand roughness $k$ are occasionally used as well, but less so in recent years, and they are not included in the most frequently used hydraulic models. The following discussion will be limited to use of the various Manning's $n$ values for the underside of the ice, $n_{\mathrm{i}}$, and the composite roughness, $n_{\mathrm{c}}$. Numerous methods of determining $n_{\mathrm{c}}$ are given in Uzuner (1975). No attempt has been made to convert roughness estimates reported in the form of $f, C$, or $k$ to $n$. Table 1 and Figure 6 summarize reported values of $n_{\mathrm{i}}$ and $n_{\mathrm{C}}$.

Roughness calculated from discharge measurements or estimates

Based on about 500 observations between 1936 and 1959, Nezhikhovskiy reports that $n_{\mathrm{i}}$ for smooth ice covers (i.e., generally formed through heat transfer processes as opposed to accumulation) ranges from 0.010 to 0.012 during initial ice cover formation and from 0.008 to 0.010 thereafter. A total of 368 measurements at 19 stations on
14 Russian rivers meeting the following criteria was used to determine $n_{\mathrm{i}}$ for rough ice covers: the ice cover was either rough or had frazil deposits, sufficient measurements were made each year to determine time-related effects, and slope was measured. The following equation obtained from the Manning formula, assuming $R_{\mathrm{i}}=y_{\mathrm{i}} / 2$, was used to calculate $n_{\mathrm{c}}$ :

$$
n_{\mathrm{c}}=0.63 \frac{y_{\mathrm{i}}^{2}{ }^{2 / 3} \sqrt{S_{\mathrm{f}}}}{v_{\mathrm{i}}}
$$

and $n_{\mathrm{i}}$ was then back-calculated using eq 13 .

Based on his results, Nezhikhovskiy concluded that the roughest ice covers were observed during the first three days of ice cover and that $n_{\mathrm{i}}$ tends to decrease over the course of the winter. Loose frazil deposits tended to smooth more rapidly than dense deposits. He also noted that the bottom of frazil deposits tended to be wavy, and that thicker deposits had larger amplitude ridges; both thick and thin deposits smoothed during the winter. By categorizing ice covers into three categories (ice covers formed primarily from loose frazil, dense frazil, and sheet ice), Nezhikhovskiy developed the curves shown in Figure 7 to describe $n_{\mathrm{i}}$ at the time of initial ice cover formation in terms of thickness. In the case of frazil accumulations or depos-

Table 1. Values of ice roughness coefficient $\left(n_{\mathrm{i}}\right)$ and composite roughness coefficient $\left(n_{\mathrm{c}}\right)$ calculated from discharge measurements.

\begin{tabular}{|c|c|c|c|}
\hline$\left(\mathrm{n}_{i}\right)$ & $\left(\mathrm{n}_{c}\right)$ & Comment & Reference \\
\hline & $0.010-0.012$ & Sheet ice, early winter* & Nezhikhovskiy (1964) \\
\hline & $0.008-0.010$ & Sheet ice, late winter & Nezhikhovskiy (1964) \\
\hline $0.010-0.06+$ & & Ice cover formed from loose frazil ${ }^{*}$ & Nezhikhovskiy (1964) \\
\hline $0.013-0.09+$ & & Ice cover formed from dense frazil* & Nezhikhovskiy (1964) \\
\hline $0.015-0.10 \dagger$ & & Ice cover formed from sheet ice* & Nezhikhovskiy (1964) \\
\hline $0.010-0.028^{* *}$ & $0.018-0.027$ & Sheet ice & Carey (1966) \\
\hline $0.004-0.013^{* *}$ & $0.015-0.022$ & Sheet ice & Carey (1967) \\
\hline 0.10 & $0.090-0.109$ & Breakup jams & Beltaos (1978) \\
\hline $\begin{array}{c}0.057-0.065 \\
\bar{n}_{\mathrm{i}}=0.060\end{array}$ & $0.041-0.046$ & Breakup jam & Andres (1980) \\
\hline $0.010-0.015$ & & Breakup jam & Knowles and Hodgins (1980) \\
\hline & $0.053-0.142$ & Breakup jams & Michel (1980) \\
\hline $0.013-0.040$ & & Freezeup jam* & Beltaos (1981) \\
\hline $0.033-0.041+\dagger$ & & Freezeup jam* & Beltaos (1983) \\
\hline 0.072 & & Breakup jams & Andres and Doyle (1984) \\
\hline $0.020-0.15$ & & Freezeup jam, frazil deposits & Majewski and Grzes (1986) \\
\hline
\end{tabular}

*Within three days of formation.

tHigher values for thicker accumulations.

** Lower values earlier in the winter.

t+Higher values for thinner accumulations. 


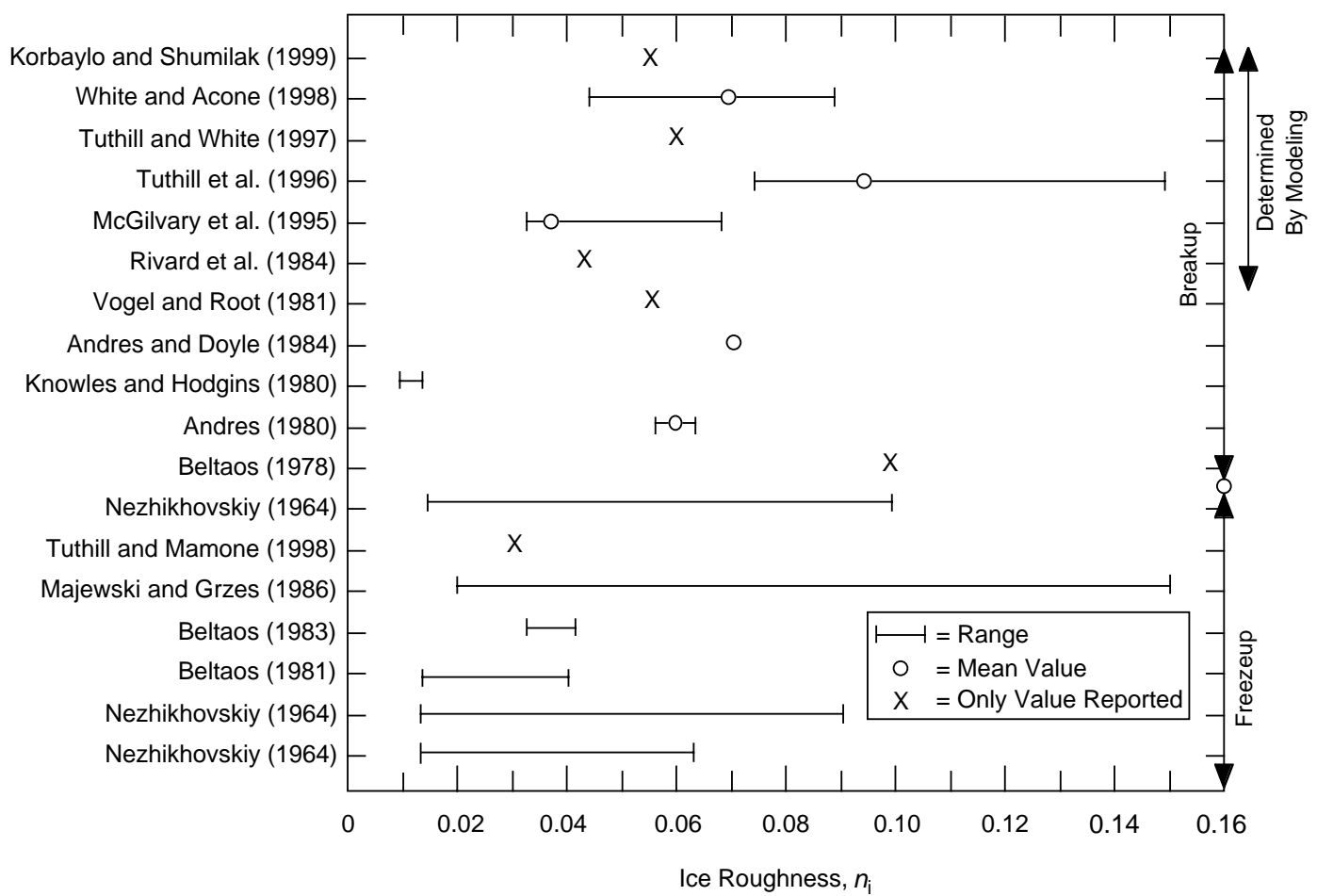

Figure 6. Reported values of ice roughness.

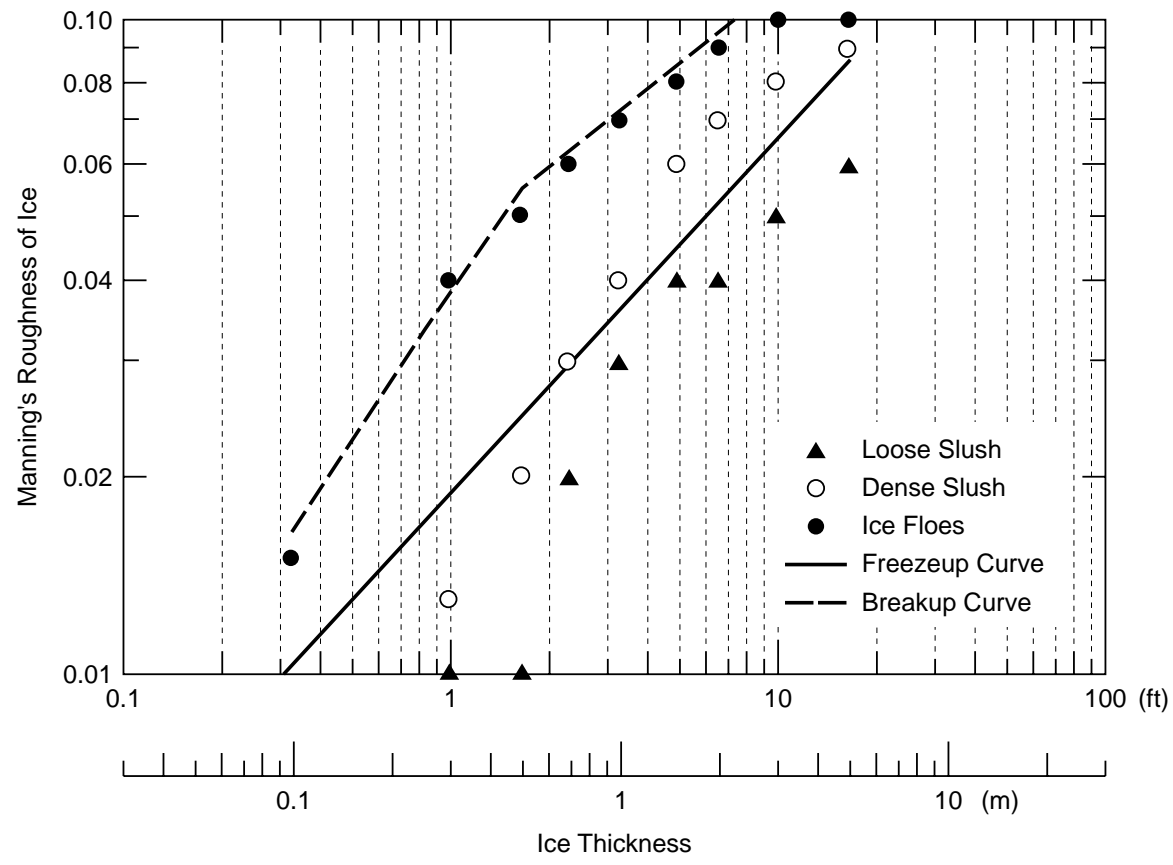

Figure 7. Nezhikhovskiy's (1964) suggested coefficients of ice roughness $\left(\mathrm{n}_{i}\right)$ at the time of initial ice cover formation, based on the thickness and type of the parent ice material. 
its, thickness is taken as the measured or estimated thickness of the ice cover, whereas for accumulations made up of broken sheet ice, thickness is that of the parent ice material. He specifically states that these data are applicable to initial ice cover formation and not to breakup jams. Because the data underlying this figure were carefully collected and the sample size was large $(n=368)$, they provide a valuable resource when selecting roughness values at the time of initial ice cover formation.

Beltaos (1981) calculated $n_{\mathrm{i}}$ for a January 1980 frazil ice jam on the Thames River, New Brunswick, using estimated discharge and thickness. Like Nezhikhovskiy, he observed that the initial roughness was the highest and that smoothing occurred over time, also three days in this case. Although four methods of estimating thickness and roughness were presented, two were considered plausible. The values of $n_{\mathrm{i}}$ ranged from 0.040 to 0.016 using equilibrium ice jam criteria and from 0.038 to 0.013 using Nezhikhovskiy's relationship between $n_{\mathrm{i}}$ and thickness. At the time of initial freezeup in 1981, Beltaos (1983) estimated that roughness was between 0.033 and 0.041 , depending on thickness.

Measurements on the Vistula River, Poland, during January 1982 allowed Majewski and Grzes (1986) to determine roughness values for a frazil ice jam. Over the course of 20 days, they found $0.020<n_{\mathrm{i}}<0.15$, with the roughest sections associated with shoved areas. Estimates based on field measurements made in 1984 and 1985 ranged from $n_{\mathrm{i}}=0.012$ for sheet ice to $n_{\mathrm{i}}=0.080$ for frozen ice floes mixed with frazil. They also noted the decrease in roughness over time.

Carey $(1966,1967)$ made careful observations of the sheet ice cover near a USGS gage on the St. Croix River, Wisconsin, during three winters (1964-66). He noted dunes and ripples on the underside of the ice, and observed that the wavelength and amplitude of the dunes and ripples near the bank were greater than for ice taken from midstream. In contrast to Nezhikhovskiy's work with frazil deposits and accumulations of frazil and sheet ice, Carey found that roughness for sheet ice covers tends to increase after ice cover formation. Using his own formulation for calculating $n_{\mathrm{i}}$ and $n_{\mathrm{C}^{\prime}}$ he reported $n_{\mathrm{i}}$ between 0.010 and 0.028 and $n_{\mathrm{c}}$ between 0.018 and 0.027 during 1964 and 1965, with lower values reported earlier in the winter (Carey 1966). Later, Carey (1967) indicated that these values may have been underreported because of an incorrect assumption in his method.
Using a modified approach, he computed $0.004<$ $n_{\mathrm{i}}<0.013$ and $0.015<n_{\mathrm{c}}<0.022$ for measurements made during 1966.

Michel (1980) states that the roughness of breakup jams will be primarily a function of the shape and size of the floes making up the jam. For example, he points out that jams made up largely of small floes will have smaller roughness than those made up of large floes. Although Michel disputes the use of the relationship suggested by Nezhikhovskiy, in fact his reliance on floe shape and size is related to Nezhikhovskiy's reliance on parent ice thickness. Michel suggests that in the case of breakup jams that are decaying, the roughness will decrease with decay. Using his own formulation, he determined values of $n_{\mathrm{c}}$ for ten locations on three Canadian Rivers ranging from 0.053 to 0.142 .

Using an approach combining elements of the Nezhikhovskiy approach, Beltaos (1978) determined $n_{\mathrm{c}}$ and $n_{\mathrm{i}}$ for two breakup ice jams on the Smoky and Wapiti Rivers, Alberta. The ice roughness, $n_{\mathrm{i}}$, was found to be constant and equal to 0.10 , while $n_{\mathrm{c}}$ varied from 0.090 to 0.109 . Using a similar approach, Andres (1980) estimated 0.057 $<n_{\mathrm{i}}<0.065\left(\bar{n}_{\mathrm{i}}=0.060\right)$ and $0.041<n_{\mathrm{c}}<0.046$ for the April 1978 Athabasca River (Alberta) breakup ice jam based on measured discharge, slope, and stage. When data from this jam were combined with 1977 and 1978 data, Andres and Doyle (1984) calculated an average $n_{\mathrm{i}}=0.072$.

The shear stress approach was used by Knowles and Hodgins (1980) to estimate $n_{\mathrm{i}}$ and the BelokonSabaneev equation to calculate $n_{\mathrm{c}}$ for two breakup jams on the Thames River, New Brunswick. They found that $n_{\mathrm{i}}$ ranged from 0.01 to 0.015 and depended on the bed roughness and the ratio of jam thickness to depth.

\section{Roughness estimated during numerical model calibration}

Vogel and Root (1981) modeled breakup jams on the Missisquoi River (Vermont) using $n_{\mathrm{i}}=0.057$. Rivard et al. (1984) used HEC-2 to model a May 1983 breakup ice jam on the Mackenzie River. The roughness $\left(n_{\mathrm{i}}\right)$ of the intact ice sheet was assumed to be 0.020 . The best fit with measured water surface profiles was found with $n_{\mathrm{i}}=0.045$ within the jam. Similarly, roughness values between 0.044 and 0.090 provided a good fit in modeling observed jam stages on the Aroostook River (White and Acone 1998). Tuthill and White (1997) used $n_{\mathrm{i}}$ $=0.060$ to model a breakup jam on the Salmon River, Connecticut. The same value was report- 
edly used by Korbaylo and Shumilak (1999) in modeling the 1986 Churchill River breakup jam. Tuthill and Mamone (1998) used a lower value, $n_{\mathrm{i}}$ $=0.030$, when modeling freezeup jams on the middle Mississippi River.

\section{Uncertainty in ice roughness}

White and Daly (1997) examined the effects of uncertainties in the estimate of ice roughness on the calculated equilibrium ice jam thickness. They obtained 46 values of $n_{\mathrm{i}}$ from calibrated numerical models of three breakup ice jams. These ranged from very smooth $(0.020)$ to very rough $(0.150)$, with a mean of 0.066 and standard deviation of 0.023 (Figure 8a). The distribution was found to be nearly normal. A Monte-Carlo simulation of sample size 10,000, based on the mean of 0.066 and standard deviation of 0.023 , is shown in Figure $8 b$.

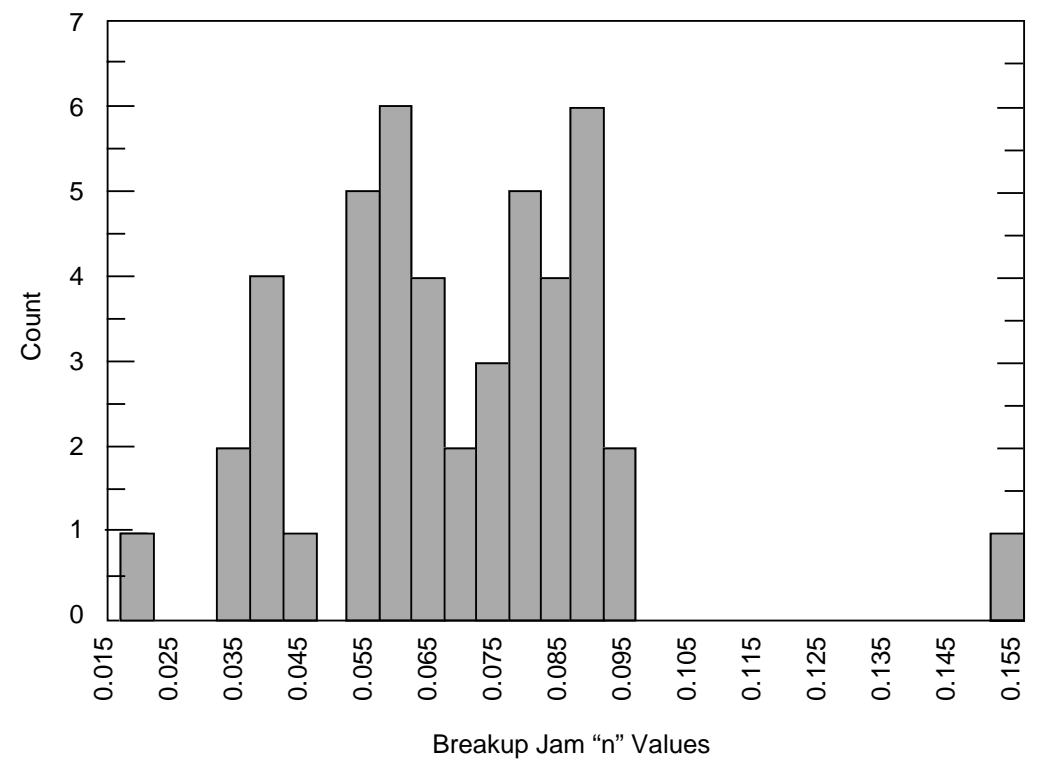

a. Distribution of Manning's $\mathrm{n}$ values for the underside of the ice from calibrated numerical models of breakup ice jams at three sites.

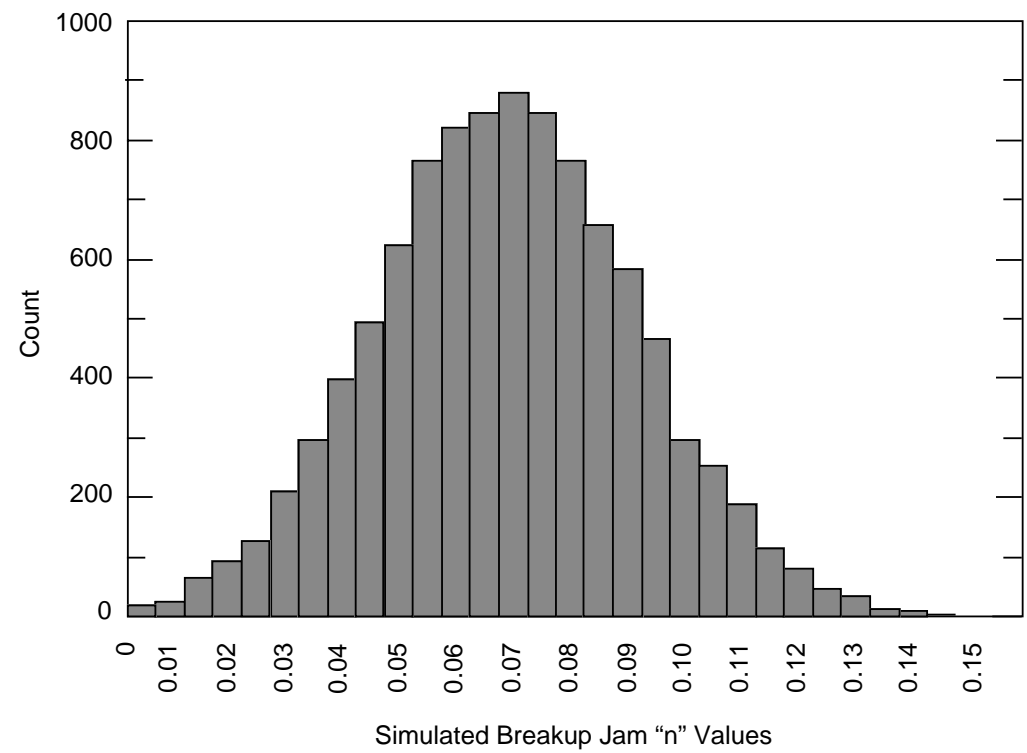

b. Distribution of simulated Manning's n values. (From White and Daly 1997.)

Figure 8. Distribution of actual and simulated Manning's n values. 
The $95 \%$ confidence interval is $(0.029,0.105)$, which can be interpreted to mean that one can be $95 \%$ confident that the Manning's $n$ values for breakup jams will lie between 0.029 and 0.105 , based on the data shown in Figure 8a.

Using these data, they simulated equilibrium ice thickness using eq 19 for a rectangular channel width of $100 \mathrm{~m}$ with $n_{\mathrm{b}}$ of 0.030 , discharge 100 $\mathrm{m}^{3} \mathrm{~s}^{-1}$, water slope $0.001 \mathrm{~m} / \mathrm{m}$, and equilibrium jam section porosity of $50 \%$. The results showed that ice thickness is relatively insensitive to changes in roughness (i.e., large differences in roughness resulted in relatively small differences in ice thickness). Stage was found to be more than twice as sensitive to roughness than ice thickness for the channel geometry tested. However, less uncertainty was associated with stage or thickness than with roughness. The opposite was reported by Healy et al. (1997), who evaluated the non-equilibrium breakup jam that occurred in 1986 on the Thames River (New Brunswick) using the Canadian model ICEJAM (Flato and Gerard 1986). They found that thickness was more sensitive to changes in roughness than stage in this situation: a change in composite roughness from 0.040 to 0.080 caused $65 \%$ change in thickness and $25 \%$ change in stage.

\section{Cohesion $\left(C_{\mathrm{i}}\right)$}

Fish and Zaretsky (1997) state that "Ice cohesion is the principal strength parameter of ice." This is immediately obvious to the observer of freezeup jam formation and progression, in which the apparent cohesive strength of the frazil floes plays a large part in ice cover accumulation. In addition, because freezeup jams most often occur at very low air temperatures, freezing at the water surface level within the accumulation can lead to rapid and large increases in strength. Tuthill et al. (1998) suggest that cohesion can range up to about $960 \mathrm{~Pa}$ to $1200 \mathrm{~Pa}$ in freezeup jams.

Yet cohesion is often neglected, particularly for breakup jams. This is partly because no actual measurements have been made. In both ICETHK and HEC-RAS, $C_{\mathrm{i}}$ is assumed to be 0 for breakup ice jams formed from unconsolidated rubble. However, some researchers have considered cohesion in breakup jams. Beltaos (1978) used a value of 96 Pa for cohesion when modeling the 1976 breakup jams on the Smoky and Wapiti Rivers (Alberta). Following his method, Andres and Doyle (1984) also accounted for cohesion in their analysis of breakup jams on the Athabasca River (Alberta) in 1977,1978 , and 1979, assuming the same value of
$C_{\mathrm{i}}=96 \mathrm{~Pa}$. Assuming a value of $\mu=1.3$, Calkins (1983) calculated $C_{\mathrm{i}}=168 \mathrm{~Pa}$ and $254 \mathrm{~Pa}$ for breakup jams on the Ottauquechee River and First Branch White River (Vermont), respectively. He concluded that cohesion in breakup jams is insignificant compared to water slope, river width, and bankfull depth. Ashton (1986) reported that laboratory results suggest that $C_{\mathrm{i}}=100 \mathrm{~Pa}$ to $500 \mathrm{~Pa}$.

\section{Coefficient of internal strength or friction $(\mu)$ and angle of internal friction $(\phi)$}

The coefficient of internal strength of the ice cover, or $\mu$, is sometimes called the friction coefficient. This coefficient is a lumped variable representing the effects of a number of unknown or difficult-to-determine factors, including lateral stress within the ice cover, ice on bank friction, angle of internal resistance, porosity, and possibly cohesion. Michel (1984) suggests that $\mu=1.3$ and $\phi=$ 30 should be used when modeling breakup jams, but a variety of values have been determined (Table 2). Based on observations of a number of jams, Beltaos (1981) hypothesized $\mu$ is important in modeling thicker jams, but less important for thinner jams. In an evaluation of 11 case studies of breakup jams, Beltaos (1982) reports a range of $0.8<\mu<1.3$, with an average of 1.2. Two other jams, for which $\mu=0.6$ and $\mu=3.5$, were presented but not included; the lower value was based on highly uncertain post-jam observations and the upper on a thin jam for which ice on bank friction may have been highly influential. Beltaos (1983, 1978) calculated $\mu=1.6$ for a 1981 breakup jam on the Thames River, New Brunswick, and 0.9 to 2.2 for breakup jams on the Smoky and Wapiti Rivers, Alberta. He used a value of $\mu=1.2$ in modeling the 1992 and 1996 Credit River (Ontario) breakup jams (Beltaos 1999).

Table 2. Values of the coefficient of internal strength $(\mu)$ calculated by various researchers.

\begin{tabular}{lcl} 
Range of $\mu$ & Mean value & \multicolumn{1}{c}{ Reference } \\
\hline $0.9-2.2$ & & Beltaos (1978) \\
& 1.0 & Andres (1980) \\
$0.8-1.3$ & 1.2 & Beltaos (1982) \\
& 1.6 & Beltaos (1983) \\
$1.6,2.0$ & & Rivard et al. (1984) \\
& 1.06 & Prowse (1986) \\
$0.8-2.7$ & 1.6 & Andres and Doyle (1984) \\
& 1.2 & Beltaos et al. (1996) \\
& 1.17 & Tuthill and White (1997) \\
& 1.5 & Korbaylo and Shumilak (1999) \\
\hline
\end{tabular}


Andres (1980) calculated $\mu=1.0$ for the 1978 breakup jam on the Athabasca River (Alberta). Later, Andres and Doyle (1984) used Beltaos' (1978) approach to determine breakup jam characteristics for the Athabasca River breakup jams in 1977 and 1979 as well as 1978, reported previously. Assuming $C_{\mathrm{i}}$ to be $96 \mathrm{~Pa}$, they found $\mu$ to range from 0.8 to 2.7 , with an average of 1.6. However, they point out that $\mu$ is very sensitive to errors in discharge, and that the unexpectedly wide range of $\mu$ is probably attributable to errors in estimating discharge. Tuthill and White (1997) reported $\mu=1.17$ when modeling a breakup jam on the Salmon River, Connecticut. Prowse (1986) calculated $\mu=1.06$ for the 1983 ice jam at the confluence of the Liard and Mackenzie Rivers, Northwest Territories, while Rivard et al. (1984) calculated higher values $(2.0,1.6)$ for two cross sections of the Mackenzie River jam that same year. Korbaylo and Shumilak (1999) used a value of $\mu=$ 1.5 when modeling the 1986 Churchill River breakup jam. Reported values of $\mu$ are summarized in Figure 9.

If the lumped variable approach is not used, the friction coefficient is calculated using the following equation using theory developed for granular materials:

$$
\mu=k_{0} K_{\mathrm{p}} \lambda(1-p)
$$

where $k_{0}$ is the coefficient of friction between ice and bank; $\lambda$ is the lateral stress coefficient, sometimes called $k_{1}$; and $K_{\mathrm{p}}$ is the passive pressure coefficient (ratio of longitudinal to vertical stress at the time of failure), labeled $k_{\mathrm{x}}$ in some models. The lateral stress coefficient is often assumed to be 0.33 (e.g., Tuthill and Mamone 1998). The coefficients $k_{0}$ and $K_{\mathrm{p}}$ are calculated by

$$
k_{0}=\tan (\phi) \text { and } K_{\mathrm{p}}=\tan ^{2}\left(45+\frac{\phi}{2}\right)
$$

where $\phi$ is the angle of internal friction in degrees. $\phi$ is sometimes approximated using the angle of repose in dry materials, and often assumed to be $45^{\circ}$ in ice. Substituting, eq 22 becomes

$$
\mu=\tan (\phi) \tan ^{2}\left(45+\frac{\phi}{2}\right) \lambda(1-p)
$$

in which the dependence of the friction coefficient on angle of internal friction can be seen.

Michel (1980) calculated an average value of $\phi$ $=21^{\circ}$ based on data from 10 jams. Weiss et al. (1981) report $11^{\circ}<\mathrm{f}<34^{\circ}$ in a series of shear box tests on ice rubble, with higher values for rubble formed from thicker parent ice sheets. Slower displacement for the same ice thickness also resulted in

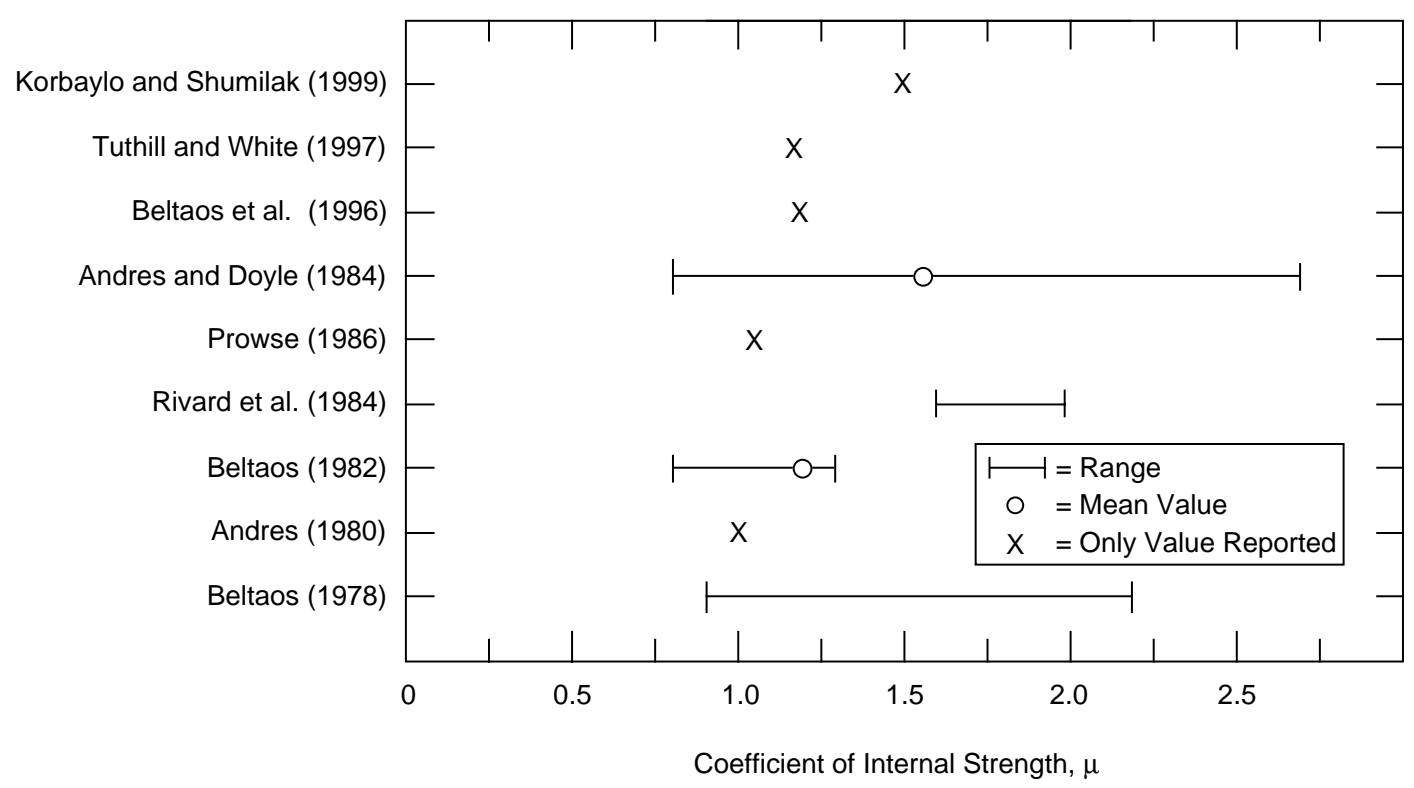

Figure 9. Calculated values of the coefficient of internal strength $(\mu)$. 
higher $\phi$. Based on laboratory shear box tests on ice rubble, Prodanovic (1979) reports $\phi=53^{\circ}$ for thicker ice and $\phi=47^{\circ}$ for thinner ice. Shear box tests by Hellman (1984), cited in Ettema and UrrozAguirre (1991), reportedly resulted in $\phi=54^{\circ}$. Ettema and Urroz-Aguirre (1991) report that freeze bonding can affect the shear and compressive strengths of ice, and suggest that the relatively high values of $\phi$ often reported are actually an effective friction angle reflecting these and other effects. Løset and Sayed (1993) conducted shear tests in a biaxial compression chamber and noted that submerged freshwater ice rubble froze, resulting in larger pieces and higher angles of internal friction than for dry rubble. They tested different size distributions of $25-\mathrm{mm}$ and $100-\mathrm{mm}$ ice blocks, and found that uniform size distributions produced higher stresses than a mixture of half large and half small blocks. Timco and Cornett (1999) conducted shear testing of broken saline and freshwater ice rubble using a biaxial compression chamber. They found that friction angle decreases with increasing strain ratio until some limiting friction angle is reached. For freshwater ice, this ranged from about $76^{\circ}$ at low strain ratio $(\approx 1.2)$ to about $38^{\circ}$ at a high strain ratio (3.5). They hypothesized that fracturing of the rubble at the higher strain ratios could explain the change in friction angle.
Table 3. Reported values of the angle of internal friction $(\phi)$ for freshwater ice.

\begin{tabular}{cll}
$\begin{array}{c}\text { Range } \\
\text { of } \phi\end{array}$ & $\begin{array}{c}\text { Mean } \\
\text { value }\end{array}$ & \multicolumn{1}{c}{ Reference } \\
& $53^{\circ}$ & Prodanovic (1979) (thicker ice) \\
$47^{\circ}$ & Prodanovic (1979) (thinner ice) \\
& $54^{\circ}$ & Hellman (1984)* \\
& $21^{\circ}$ & Michel (1980) \\
& & Weiss et al. (1981) \\
$11^{\circ}-34^{\circ}$ & & Løset and Sayed (1993) \\
$44^{\circ}-58^{\circ}$ & & Timco and Cornett (1999) \\
$38^{\circ}-76^{\circ}$ & &
\end{tabular}

*Cited in Ettema and Urroz-Aguirre (1991).

Reported values of $\phi$ are summarized in Table 3 and Figure 10.

The angle of internal friction and the passive pressure coefficient are related as shown in eq 23 (Fig. 11). Some researchers report $K_{\mathrm{p}}$ rather than $\phi$. Beltaos (1988) has calculated values of $K_{p}=8$ and 10 for a refrozen breakup jam on the Thames River, New Brunswick, with $K_{\mathrm{p}}=9.6$ providing the best model results using RIVJAM. Beltaos and Burrell (1991), Beltaos (1993), and Beltaos et al. (1996) used $K_{p}=10,12,12$, and 12 when using RIVJAM to model four other breakup jams. For the 1992 and 1996 Credit River (Ontario) breakup

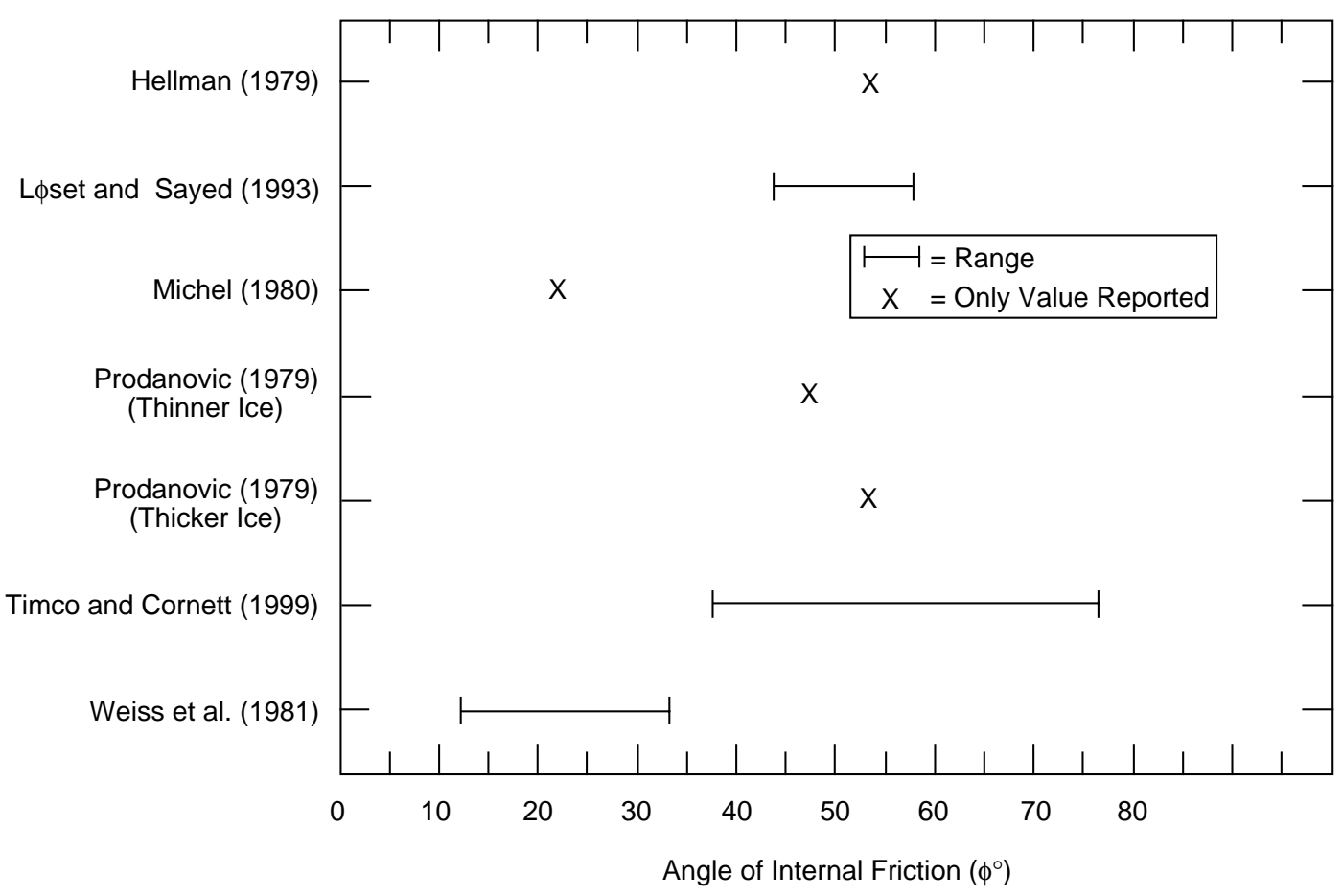

Figure 10. Reported values of the angle of internal friction, $\phi$, for freshwater ice. 


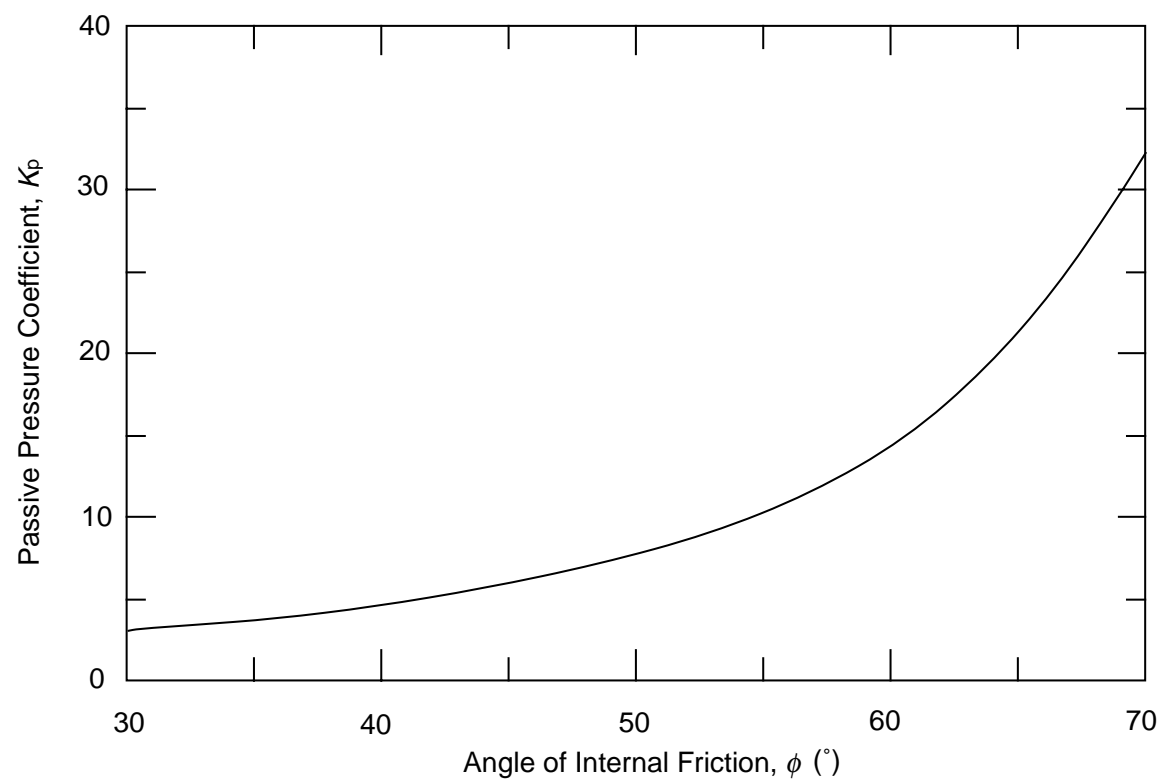

Figure 11. Relationship between angle of internal friction, $\phi$, and passive pressure coefficient, $\mathrm{K}_{\mathrm{p}}$.

jams, Beltaos (1999) used $K_{\mathrm{p}}=12$. Healy et al. (1997) evaluated the non-equilibrium breakup jam that occurred in 1986 on the Thames River (New Brunswick) using the Canadian model ICEJAM (Flato and Gerard 1986). They found that jam thickness and stage were relatively insensitive to changes in $K_{\mathrm{p}}$ as it was varied from 8 to 12 . Tuthill and Mamone (1998) used a value of $K_{\mathrm{p}}=5.83$, corresponding to $\phi=45^{\circ}$, when modeling freezeup jams on the middle Mississippi River.

\section{Porosity $(p)$}

The porosity of an ice accumulation is used in estimating the volume of ice contributing to the ice accumulation and in determining such variables as its coefficient of internal strength. Porosity is described by

$$
p=\frac{V_{\mathrm{v}}}{V_{\mathrm{t}}}=1-\frac{V_{\mathrm{i}}}{V_{\mathrm{t}}}
$$

where $V_{\mathrm{v}}$ is the volume of voids, both above and beneath the water surface, $V_{\mathrm{i}}$ is the volume of the ice, and $V_{\mathrm{t}}$ is the total volume of the jam. As Beltaos (1995) noted, the porosity of an ice jam can be much larger than the porosity of the floes comprising the jam. Few field measurements of porosity exist; most reported values are either assumed or back-calculated from measurements of other ice variables. In some cases, density $(D)$ of frazil deposits or accumulations has been reported. Density and porosity are related as follows:

$$
p=1-\frac{D}{\rho_{\mathrm{i}}} .
$$

Reported values of porosity discussed below are summarized in Table 4 and Figure 12.

Freezeup ice jams and frazil deposits

Petryk (1995) reports that ICESIM uses a value of 0.73 in modeling porosity of ice jams formed from undercover deposition of frazil. This value was in the range of 0.65 to 0.85 that Beltaos (1995) calculated from data reported in Kivisild (1959). Beltaos and Dean (1981) made bulk measurements in a thick (16-m) frazil deposit and found porosities of 0.541 and 0.33 for the bottom and top of the deposit, respectively. They also reported densities of 400 to $600 \mathrm{~kg} / \mathrm{m}^{3}$, with lower densities near the bottom of the deposit and higher densities just below the surface of the ice cover. Majewski and Grzes (1986) measured density along a 42-km-long freezeup jam on the Vistula River (Poland) between Wloclawek and Plock and found a wide range of density in deposits and a narrow range of density in shoved areas. They reported that density of hanging dams ranged from 100 to 700 
Table 4. Reported measured or estimated values of porosity.

\begin{tabular}{lcl} 
Jam type & Porosity & \multicolumn{1}{c}{ Reference } \\
\hline $\begin{array}{l}\text { Frazil deposit } \\
\quad \text { (bulk measurement) }\end{array}$ & $0.33,0.51$ & Beltaos and Dean (1981) \\
Ice rubble & $0.19-0.50$, & Weiss et al. (1981) \\
& $\bar{p}=0.34$ & \\
Frazil deposit & $0.32-0.67$ & Dean (1986) \\
Frazil deposit & $0.24-0.89$ & Majewski and Grzes (1986) \\
$\begin{array}{l}\text { Frazil accumulated } \\
\text { by shoving }\end{array}$ & $0.35-0.45$ & Majewski and Grzes (1986) \\
$\begin{array}{l}\text { Breakup jam } \\
\text { Frazil deposit }\end{array}$ & $0.38 \pm 0.1$ & Prowse (1990) \\
$\quad$ (borehole dilution test) & $\bar{p}=0.59$ & White and Lawson (1992) \\
$\begin{array}{l}\text { Frazil deposit } \\
\quad \text { (bulk measurement) }\end{array}$ & $0.35-0.77$, & White and Lawson (1992) \\
$\begin{array}{l}\text { Freezeup jam } \\
\text { Frazil deposits }\end{array} \quad \bar{p}=0.52$ & Shen and Wang (1992) \\
$\quad$ laboratory) & 0.40 & Andersson and Daly (1992) \\
Breakup jam & $0.67 \pm 0.13$ & Lever and Gooch (1998) \\
$\quad$ (groundwater flow theory) & $0.70 \pm 0.2^{*}$ & \\
\hline
\end{tabular}

*May be high due to incomplete grounding or piping through jam.

$\mathrm{kg} / \mathrm{m}^{3}(0.89<p<0.24)$, while the shoved sections of the jams were more dense, between 500 and 600 $\mathrm{kg} / \mathrm{m}^{3}(0.45<p<0.35)$.

Although Michel (1984) states that Kivisild's reported porosity values and his own value of 0.75 represented reasonable values for freezeup jams, smaller values of frazil deposit porosity are reported by several researchers. Based on data from borehole dilution tests of frazil accumulations in the laboratory, White (1991) estimated mean porosity to be 0.44 , using the Kozeny-Carmen equation and an assumed particle diameter of $0.2 \mathrm{~mm}$.

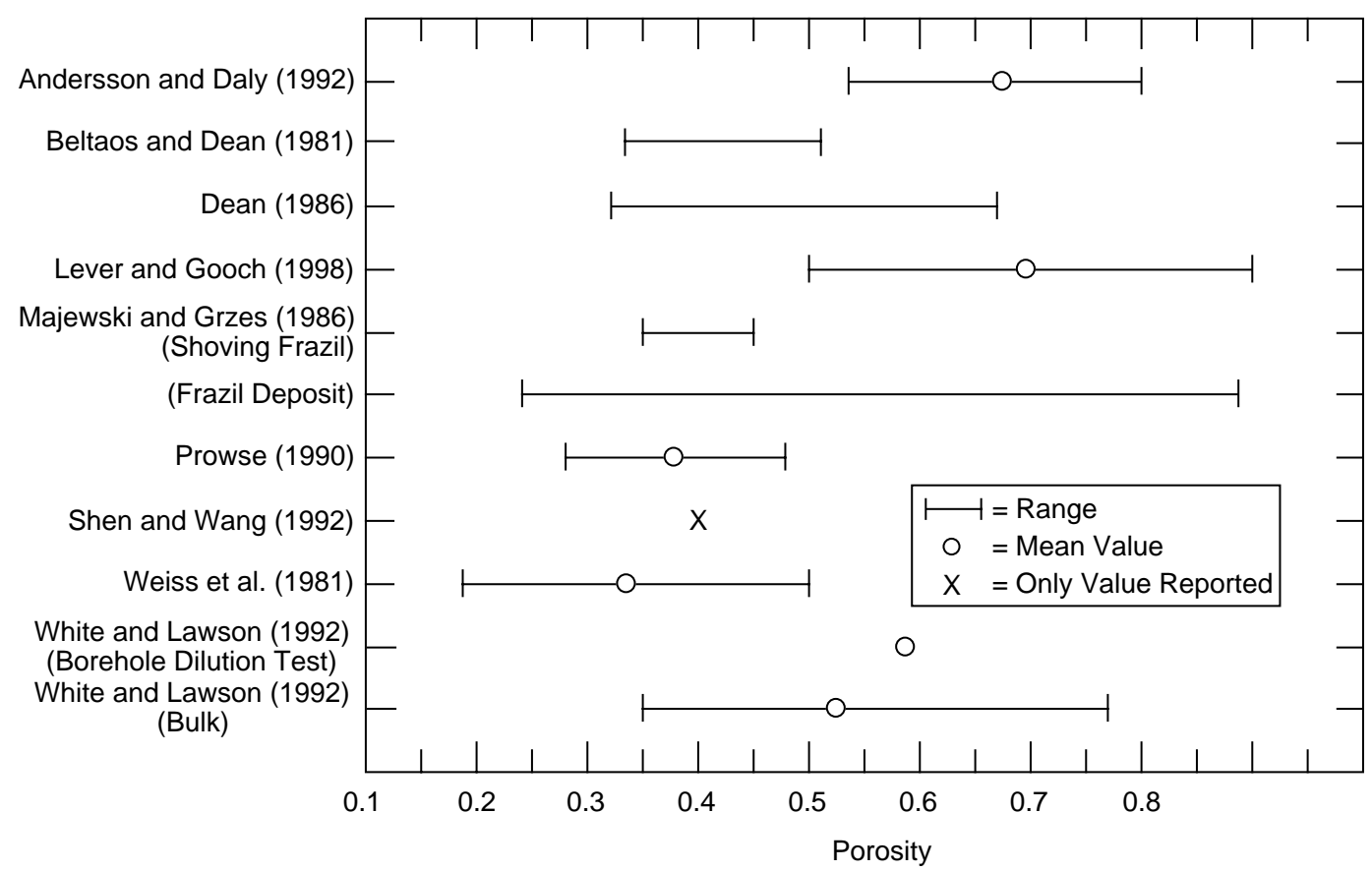

Figure 12. Reported porosity measurements and estimates. 
Using the same method, White and Lawson (1992) calculated an average porosity of 0.59 for a latewinter frazil deposit on the Tanana River, Alaska. This compared favorably to porosities determined by direct measurement of ice and water volumes in bulk samples, which ranged from 0.35 to 0.77 , with an average of 0.52 . Based on field measurements, Shen and Wang (1992) reported porosity of 0.4 for a freezeup jam on the Yellow River, China (no method was specified). Tuthill et al. (1998) suggest a range of 0.5 to 0.7 for frazil pans at freezeup when using ICETHK. Tuthill and Mamone (1998) used $p=0.5$ when modeling a freezeup jam on the middle Mississippi River. Measurements of the porosity of frazil ice deposits formed on trash racks in the laboratory were made by Andersson and Daly (1992) using a modified CRREL snow density kit. They measured 20 samples and found a mean porosity of 0.67 (Fig. 13).

\section{Breakup ice jams and ice rubble}

Weiss et al. (1981) measured porosity for manufactured ice rubble of different parent ice sheet thickness. They found porosity ranging from 0.19 to 0.50 , with an average value of 0.34 . Higher porosity was generally associated with thicker parent ice. Prowse (1988) developed a method to esti- mate porosity of breakup ice jams based on the energy and mass balance of an ablating ice jam at the confluence of the Liard and MacKenzie Rivers (Northwest Territories) in 1983. He reported an average porosity of 0.35 . Because the uncertainty of the method is largely attributable to air temperature, he varied his mean temperature by $\pm 5^{\circ} \mathrm{C}$, with a resulting range of porosity from 0.26 (warmer water temperatures) to 0.44 (cooler water temperatures). Upon improving the method (Prowse and Marsh 1989, Prowse 1990), the range of porosity was found to be $0.38 \pm 10 \%$, quite close to the commonly assumed value of 0.4 (e.g., Beltaos 1978, 1995, 1999). Michel (1980, 1984) and Tuthill et al. (1998) suggested porosity values of 0.4 to 0.5 when modeling breakup jams. Tuthill et al. (1996) used $p=0.5$ in the hydraulic modeling of a breakup ice jam.

\section{Grounded jams}

Porosity is particularly important in the case of breakup ice jams that are grounded, because permeability varies with porosity and hence discharge will also vary with porosity, affecting backwater levels upstream from a grounded jam. Wong et al. (1985) and Beltaos $(1993,1999)$ used a theoretical model of porous flow presented by Bear (1972) in which porosity is related to seepage flow:

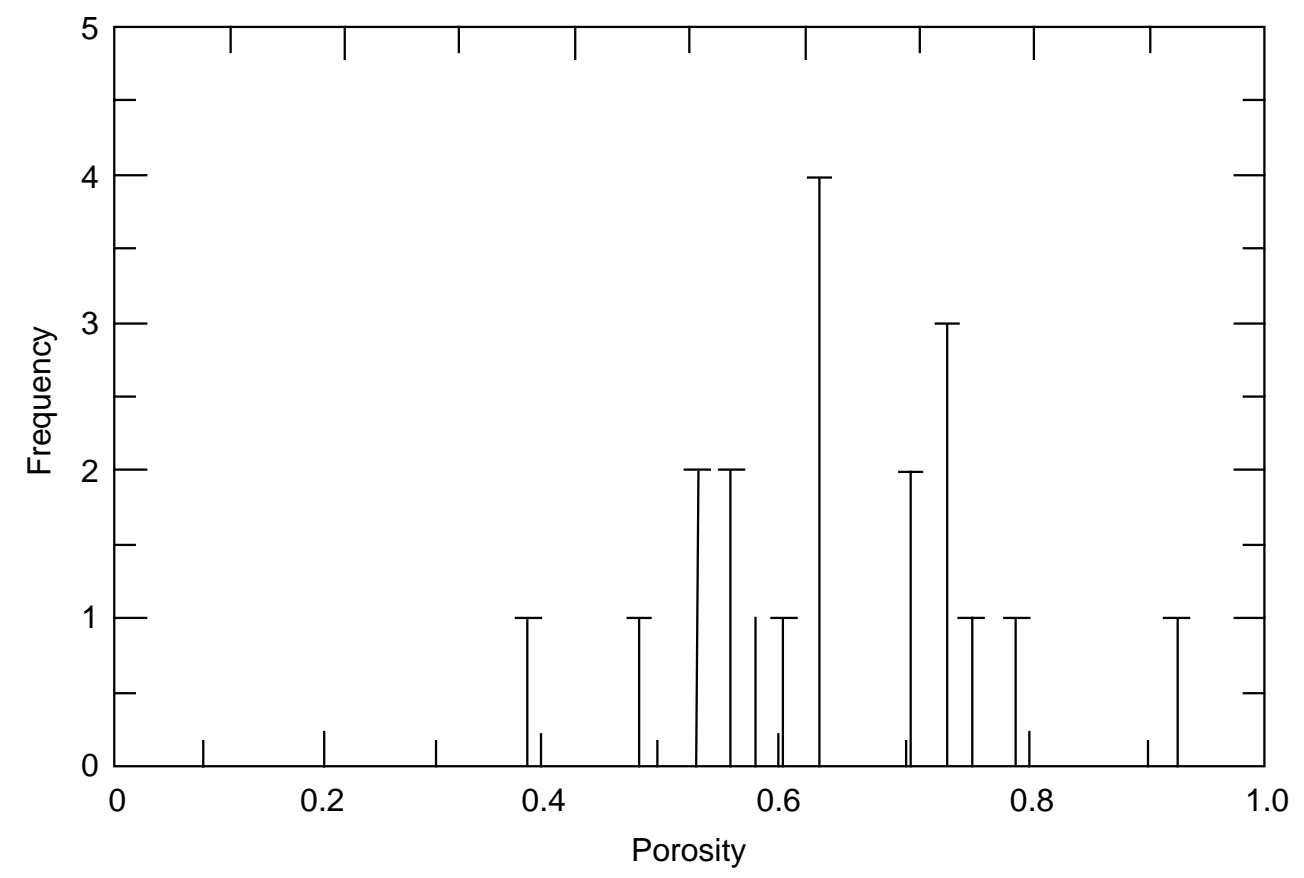

Figure 13. Porosity measurements of frazil deposits formed on trashracks in the CRREL refrigerated flume. (From Andersson and Daly 1992.) 


$$
\frac{p^{3}}{1-p}=\frac{\lambda^{2}}{K g d_{\mathrm{s}}}
$$

where $\lambda$ is the seepage coefficient, $K$ is a dimensionless seepage coefficient, and $d_{\mathrm{s}}$ is a variable describing the particles $\left(d_{\mathrm{s}}=6 / M_{\mathrm{s}}\right.$, where $M_{\mathrm{s}}$ is the specific area per unit volume of the solid particles, or the ratio of surface area to volume). In tests with square polyethylene blocks, Wong et al. (1985) found that $K$ varied from 0.3 to 0.7 , with the higher value for randomly placed blocks. Beltaos (1999) suggested that $d_{\mathrm{s}}$ can be approximated as twice the average ice thickness of the ice blocks. This approach was used by Lever and Gooch (1998), who obtained careful water level measurements and discharge estimates at rated cross sections for a breakup jam thought to be grounded at the toe. Assuming $K=0.6$ and $d_{\mathrm{s}} \approx$ twice the average parent ice thickness, they calculated $p=0.70 \pm 0.2$. However, this high value for breakup jam porosity may be a result of incomplete grounding or piping through the jam, because the analysis includes only porous flow.

\section{Shear stress on the underside of the ice cover $(\tau)$}

As noted in eq 18, the shear stress on the underside of the ice cover, $\tau$, is a function of $\rho, g, S_{\mathrm{f}}$, and the variables necessary to calculate $R_{\mathrm{i}}: q, n_{\mathrm{i}}$, $n_{\mathrm{b}}$, and $n_{\mathrm{c}}$. Based on observed water profiles, Andres (1980) calculated $\tau=18.6 \mathrm{~Pa}$ for the 1978 Athabasca River (Alberta) breakup jam. Andres and Doyle (1984) report a range of 9.6 to $28.5 \mathrm{~Pa}$ and an average of $17.9 \mathrm{~Pa}$ for shear forces experienced during breakup jams on the Athabasca River (Alberta) in 1977, 1978, and 1979. Rivard et al. (1984) calculated $\tau=7.21 \mathrm{~Pa}$ and $\tau=10.0 \mathrm{~Pa}$ for two cross sections of the 1983 Mackenzie River (Northwest Territories) ice jam. Dean (1986) estimated shear beneath frazil ice deposits to be about 8 to $10 \mathrm{~Pa}$ during steady midwinter flow and 60 to $700 \mathrm{~Pa}$ during a severe water level change.

\section{Frazil particle diameter $(d)$ and fall velocity coefficient $\left(C_{\mathrm{f}}\right)$}

Few values of frazil particle sizes exist outside Alaska. Gosink and Osterkamp (1983) reported frazil particle diameters ranging between 1 and 6 mm during a series of tests on the Chatanika River, Alaska. Chacho et al. (1986) reported frazil diameters of $5 \mathrm{~mm}$ to $150 \mathrm{~mm}$ in the Tanana River. White and Lawson (1992) cited unpublished data by Lawson and Brockett that report particles between $1 \mathrm{~mm}$ and $25 \mathrm{~mm}$ in diameter, also on the Tanana River, Alaska. They found mean particle sizes be- tween $2 \mathrm{~mm}$ and $8 \mathrm{~mm}$ determined by sieve analyses on the samples. Beltaos and Dean (1981) reported smaller diameter particles ( $1 \mathrm{~mm}$ to $6 \mathrm{~mm}$ ) in a frazil deposit on the Smoky River, Alberta, with $60 \%$ by weight in the range of 1.1 to $2.4 \mathrm{~mm}$. Shen and Wang (1992) reported mean particle diameter of about $1 \mathrm{~cm}$ on the Yellow River, China. The fall velocity coefficient $\left(C_{\mathrm{f}}\right)$ for particles $5 \mathrm{~mm}$ to $1 \mathrm{~cm}$ in diameter has been reported to be about 1.0 (Shen and Wang 1995).

\section{MISCELLANEOUS VARIABLES AFFECTING RIVER ICE HYDRAULICS}

\section{Anchor ice growth}

Anchor ice growth occurs when frazil ice adheres to rocks or other materials on the bed of a river. The presence of anchor ice, or frazil ice accumulated on submerged surfaces, can affect river hydraulics in a number of ways, through increasing the effective bed level and changing the effective bed roughness, among others. Brown et al. (1953) reported that frazil ice adhered first on the upstream face of stones on the riverbed, or at the point of attachment to the bed for other submerged objects. Measurements showed that the average velocity at the attachment points on the upstream face of the stones was $0.40 \mathrm{~m} / \mathrm{s}$ compared to 0.77 $\mathrm{m} / \mathrm{s}$ along the sides (where anchor ice accumulated later). Under favorable conditions the anchor ice grew both horizontally and vertically to form a mat of anchor ice. Anchor ice thickness appeared to be a function of water depth, temperature, and velocity, and reached $0.6 \mathrm{~m}$ in one location.

Data from Hirayama et al. (1997) from the Niuppu River, Japan, indicate an apparent average density of about $0.5 \mathrm{~g} / \mathrm{cm}^{3}$ for anchor ice. They also reported that the density of anchor ice appears to increase slightly as water velocity increases. Using a six-hour freezing index $\left(F I\right.$, units $\left.{ }^{\circ} \mathrm{C} \mathrm{hr}\right)$ for the hours 0000 to 0600 , they measured an average anchor ice accumulation rate of $0.10 \mathrm{~m}^{3}$ per ${ }^{\circ} \mathrm{C} \mathrm{hr}$. Anchor ice accumulation was observed to be related to Froude number, $F$, as well as FI. Accumulations occurred for $0.2<F<1.5$, but none were seen for $F<0.2$. A high $F I$ (i.e., more intense cold) allowed frazil ice to accumulate at lower values of $F$, but lower FI required a higher $F$ before anchor ice accumulation was seen. Finally, they noted that more anchor ice volume results on surfaces with higher coefficients of static friction.

Kerr et al. $(1997,1998)$ investigated anchor ice growth on rounded gravel averaging 4.45 and 
$10.16 \mathrm{~cm}$ in diameter in a refrigerated flume. They observed a definite increase in effective bed elevation because of anchor ice formation, but the preliminary results were inconclusive regarding roughness effects. Anchor ice was observed to initiate and accumulate at $0.14<F<0.57$. Three different types of anchor ice were observed: compact, relatively stable growth in the form of "balls" of frazil attached to rocks at $F \geq 0.56$; a loose, relatively unstable growth at $F<0.2$ when loose, porous tails formed; and a transitional stage during which the tails either flattened out to form a mat or were released (Fig. 14). According to Daly, the loose accumulations were very unstable and tended to release in large sheets. The loose accumulations also seemed to increase effective bed roughness compared to the compact and transitional-type growth, which tended to smooth the bed, thereby increasing velocities and decreasing stage. White et al. (1999) performed a series of tests in the same flume using cobbles of median diameter $4 \mathrm{~cm}$. They reported little growth at a Froude number of about 0.21 and compact or transitiontype growth that eventually formed a mat of an-

*Personal communication, Steven F. Daly, Ice Engineering Research Division, CRREL, Hanover, New Hampshire, 1999. chor ice at a Froude number of about 0.37 , within the range reported by Hirayama et al. (1997).

\section{Jam erosion}

Frazil ice and ice pieces deposited beneath an ice cover can erode under certain conditions. Erosion, like early efforts to quantify deposition beneath ice covers, is most often described in terms of an erosion velocity. Unlike HEC-RAS, ICETHK and ICESIM do provide for erosion of deposited ice through the use of a critical velocity criterion. ICETHK uses the following equation, developed from continuity:

$$
\eta_{\mathrm{t}}=\frac{1}{s_{\mathrm{i}}}\left[H-\left(\frac{v}{v_{\mathrm{e}}}\right)\left(H-s_{\mathrm{i}} \eta\right)\right]
$$

where $\eta_{t}$ is the ice thickness after thinning by erosion and $v_{\mathrm{e}}$ is the critical erosion velocity (Tuthill et al. 1998). The critical erosion velocity is thought to increase over the course of a winter and also to vary by ice type. Tuthill et al. (1998) suggest values of $v_{\mathrm{e}}$ between 0.9 and $1.5 \mathrm{~m} / \mathrm{s}$ for freezeup jams and $1.2<v_{\mathrm{e}}<2.4 \mathrm{~m} / \mathrm{s}$ for breakup jams. Petryk (1995) reports use of a critical erosion velocity of $1.1 \mathrm{~m} / \mathrm{s}$ for modeling erosion of frazil deposits on the Peace River using the SIMGLACE model.

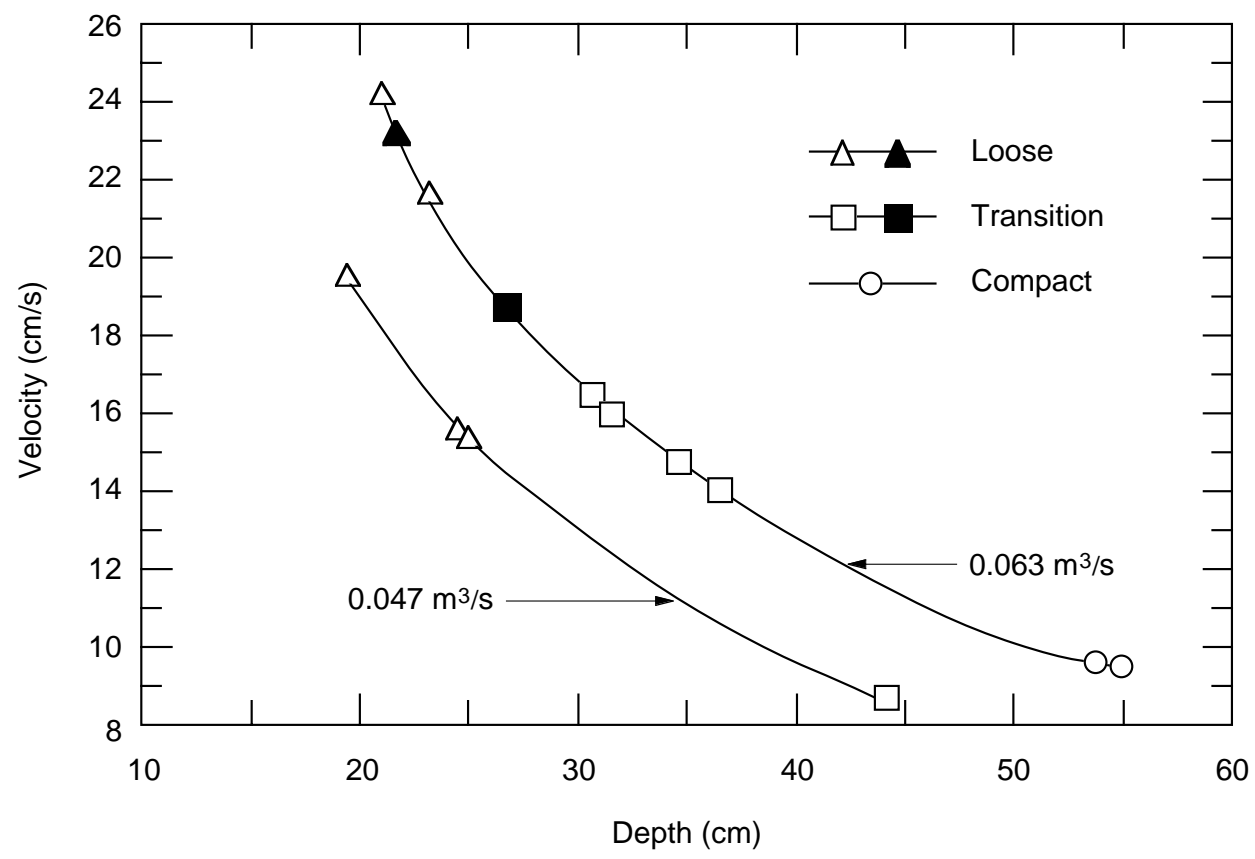

Figure 14. Anchor ice growth characteristics at different flow velocities and flow depths from Kerr et al. 1998 (open markers) and White et al. 1999 (solid markers). 


\section{Ice cover breakup and movement}

Well-documented observations of ice cover breakup, movement, and jamming are provided by Beltaos (1981) for the 1980 Thames River (New Brunswick) breakup. The candled, relatively weak ice cover was observed to lift, crack, and move downstream at a rate of about 0.6 to $0.9 \mathrm{~m} / \mathrm{s}$. Downstream movement averaged about $0.8 \mathrm{~m} / \mathrm{s}$, with some consolidation noted at $0.3 \mathrm{~m} / \mathrm{s}$. Once jammed, the jam progressed upstream at about 0.9 $\mathrm{m} / \mathrm{s}$. The velocity of two different jam releases (in different places) was also about $0.9 \mathrm{~m} / \mathrm{s}$. In 1981, the ice cover was observed to lift and crack, but not break, for water level rises of 1 to $2 \mathrm{~cm} / \mathrm{hr}, 3$ to $5 \mathrm{~cm} / \mathrm{hr}, 5.5 \mathrm{~cm} / \mathrm{hr}, 7$ to $9 \mathrm{~cm} / \mathrm{hr}$, and $8 \mathrm{~cm} / \mathrm{hr}$ at different times (Beltaos 1983). Surface movement of broken ice was observed at velocities of up to $1.2 \mathrm{~m} / \mathrm{s}$. The velocity of an ice run caused by the failure of an upstream jam was about $1.7 \mathrm{~m} / \mathrm{s}$. The same velocity was reported by Hicks et al. (1997) for an ice run caused by the failure of a 1993 ice jam on the St. John River, Maine and New Brunswick.

Andres and Doyle (1984) reported average sustained velocity of the ice cover breakup front on the Athabasca River (Alberta) to be $3.7 \mathrm{~m} / \mathrm{s}$ and $3.3 \mathrm{~m} / \mathrm{s}$ during 1978 and 1979, respectively. Higher values were observed for short durations: $5.5 \mathrm{~m} /$ s in 1977 and 1979, and $5.0 \mathrm{~m} / \mathrm{s}$ in 1978. Observations of the speed of the peak discharge and the ice front following the failure of a 1995 breakup jam on the Porcupine River, Yukon, were reported by Jasek (1997). He noted that the peak discharge arrived faster $(5.4 \mathrm{~m} / \mathrm{s})$ than the ice front $(4.2 \mathrm{~m} /$ s). Ferrick et al. (1996) used a Doppler radar system to measure the movement of a breakup ice run (March 1993) and a frazil ice run (December 1993) on the Connecticut River, New Hampshire. Velocities during the breakup run varied from 1 $\mathrm{m} / \mathrm{s}$ to $2.5 \mathrm{~m} / \mathrm{s}$ with a mean velocity of $1.35 \mathrm{~m} / \mathrm{s}$. The frazil run was slower, ranging from $0.5 \mathrm{~m} / \mathrm{s}$ to $0.65 \mathrm{~m} / \mathrm{s}$ with a mean of $0.54 \mathrm{~m} / \mathrm{s}$, which compared well with estimates made from video recordings that averaged $0.52 \mathrm{~m} / \mathrm{s}$.

\section{Coefficient of ice loss $\left(c_{1}\right)$}

The breakup and movement of an ice cover often results in the stranding of ice along the banks in the form of shear walls or ice that was carried overbank and deposited in the floodplain. It is also likely that warm temperatures during breakup may melt ice pieces travelling relatively long distances. Ice loss due to stranding and melting can decrease the ice supply available for downstream jamming and thus is of interest when estimating ice jam volume. Ice loss during breakup and ice cover movement can be described using an ice loss coefficient, $c_{1}$ :

$$
c_{1}=\frac{V_{\mathrm{t}}-V_{\mathrm{j}}}{V_{\mathrm{t}}}
$$

where $V_{\mathrm{t}}$ is the total upstream ice supply and $V_{\mathrm{j}}$ is the volume of ice contained in the jam.

The ice loss coefficient is expected to be low for shallow, steep rivers with short reaches of contributing ice cover and higher for more gently sloping rivers with longer reaches of contributing ice cover, many tributaries, and/or low banks (USACE 1982). Using a porosity of 0.40, Prowse (1986) estimated that loss coefficients ranged from 0.90 to 0.93 for ice jam volume and ice supply data collected by Calkins (1978) on the relatively short, steep White River (Vermont). Based on data from Beltaos (1983) and assuming a porosity of 0.40 , Prowse (1986) estimated a loss coefficient of 0.81 for the Liard River mainstem (British Columbia and Northwest Territories) during the breakup of 1983 , but he also reported an ice loss of about $40 \%$ in one day as ice melted, became stranded, or was broken into small enough pieces to be transported beneath the jam.

\section{Shear strength}

Beltaos and Dean (1981) measured shear strength within a thick (up to $16 \mathrm{~m}$ ) frazil deposit on the Smoky River, Alberta, using an experimental shear vane. They found that shear strength varied from year to year and also that it tends to increase with height above the bottom of the accumulation. Reported values ranged up to about $80 \mathrm{kPa}$. According to Dean (1986), the shear strength of loose, freshly deposited frazil is on the order of $10 \mathrm{~Pa}$, while an undisturbed, undegraded frazil accumulation will have a shear strength of about 30 to $60 \mathrm{kPa}$. Compacted frazil accumulations are said to attain a shear strength of about 75 $\mathrm{kPa}$. Thermal degradation will reduce shear strength in frazil deposits to between 1 and $10 \mathrm{kPa}$.

Solid ice covers have much higher levels of shear strength than frazil deposits. Based on observations of the speed of the moving ice front for breakup ice jams on the Athabasca River (Alberta) during 1977, 1978, and 1979, Andres and Doyle (1984) estimated the strength of the ice cover at between 310 and $650 \mathrm{kPa}$ for $1-\mathrm{m}$ nominal ice thickness. They reported that these values were reason- 
able compared to estimates made by others from force measurements on piers at a downstream bridge.

\section{Thermal effects on ice jams}

Once an ice cover or ice accumulation has formed, it will thicken largely because of heat transfer processes, which Ashton (1986) identified as shortwave (solar) radiation, longwave radiation, evaporation or condensation, convection, and precipitation. Ice cover decay is also a function of heat transfer processes, but it is more complicated because melting at both the top and bottom surface of the ice, and melting within the ice cover matrix itself are involved. Calculating a detailed heat budget that describes the decay process can be quite complex, because it depends on latitude, time of year, time of day, hours of sunlight, cloud cover, wind speed, air temperature, water temperature, humidity, ice type, and other variables. Solar radiation plays an important role in the heat budget, particularly in the spring when the hours of daylight are increasing, because melting within the ice cover is largely caused by increased absorption of solar radiation. This internal melting process reduces the internal strength of the ice cover and its resistance to failure at low stress levels.

\section{Heat flux}

Huokuna (1988) reported on the modeling of ice cover growth and decay on a 37.6-km reach of the Oulujoki River, Finland. The heat flux between the water and air includes contributions from short- and longwave radiation, convection, and evaporation. A heat flux of $2 \mathrm{~W} / \mathrm{m}^{2}$ was assumed between the water and the channel bed. The heat flux between the water and the ice cover is a function of flow turbulence and water temperature. The model assumed the thermal conductivity of the (snow-covered) ice cover to be $1.8 \mathrm{~W} / \mathrm{mK}$, compared to $2.24 \mathrm{~W} / \mathrm{mK}$ for pure ice. Calculated ice thickness resulting from thermal decay at two cross sections compared favorably to observed ice thickness. Careful measurements of the decay of the pre-breakup ice cover and the 1983 jam at the confluence of the Liard and Mackenzie Rivers (Northwest Territories) provided information used in determining the magnitude of the major heat fluxes contributing to ice decay (Prowse 1988, 1990; Prowse and Marsh 1989). Between 6 May and 9 May 1983, approximately $3.24 \times 107 \mathrm{~m}^{3}$ of ice melted.
Albedo

The absorption of solar radiation by an ice cover is a function of the reflectivity of its surface. Different surfaces (e.g., water, snow, ice) reflect solar radiation to different degrees. The ratio of the solar radiation reflected by a given surface to the incoming solar radiation is termed the albedo of the surface. A high albedo indicates high reflectivity (and low absorption), while a low albedo indicates low reflectivity (and a high degree of absorption). The albedo depends on both the condition of the surface (i.e., rough, smooth) and the sun angle. According to Williams and Gold (1963), the albedo of new snow is about 0.8 to 0.9 , compared to an albedo of 0.4 to 0.6 for melting snow, and 0.05 to 0.15 for water. Gray and Male (1981) report albedos of 0.75 to 0.95 for fresh snow, 0.3 to 0.4 for sea ice, and 0.05 to 0.30 for water. Kondratyev (1954), as presented in Gray and Male (1981), reports an inverse relationship between sun angle and albedo. Measured albedo increased from 0.86 to 0.95 for compact, dry, clean snow as the sun angle decreased from 30.3 to 25.1 degrees. They reported smaller increases for wetter and more porous snow. Measurements of albedo for brash ice reported in Prowse and Marsh (1989) ranged from 0.04 to 0.15 , with a mean value of 0.08 . Candled thermally grown ice had an albedo of 0.39 , while granular thermally grown ice had an albedo of 0.55 . During an ice dusting operation on the Platte River, Nebraska, the albedos of dusted and non-dusted areas were measured between 1 March and 7 March 1979 (USAED Omaha 1979). The average albedo of the non-dusted ice decreased during the measurement period from about 0.65 on 1 March to 0.40 on 5 March, probably because of the formation of pools of water on the ice surface from rainfall, snowmelt, and ice melting. The albedo of the dusted ice was about 0.2 to 0.25 .

\section{Photosynthetically active radiation (PAR)}

The presence of an ice cover is thought to prevent or minimize photosynthesis through the absorption or reflection of solar radiation in the form of visible light. The wavelengths from approximately 380 to $760 \mathrm{~nm}$ are used by photosynthetic organisms located throughout the water column (Brock et al. 1984, Atlas and Bartha 1998), with the range between 400 and $700 \mathrm{~nm}$ known as photosynthetically active radiation (PAR). Bolsenga et al. $(1991,1996)$ reported that transmittance of PAR through clear freshwater ice ranged from less than 
$2.5 \%$ for snow-covered ice up to $85 \%$ through 21 cm- (8.3-in.-) thick clear ice. Transmittance through clear ice on both clear and cloudy days was slightly higher for clear days in the upper $2 \mathrm{~m}(6.6 \mathrm{ft})$ of depth and was not significantly different below that point. No actual values of incident or transmitted PAR were reported. Vincent et al. (1998) reported transmittance of $\sim 1 \%$ to $\sim 10 \%$ in four Antarctic freshwater lakes, with PAR of about 80 $\mu \mathrm{mols} / \mathrm{m}^{2}$ at $10-\mathrm{m}(32.8-\mathrm{ft})$ depth in Lake Vanda and about $8 \mu \mathrm{mols} / \mathrm{m}^{2}$ at $5-\mathrm{m}$ (16.4-ft) depth in Lake Bonney. White and Melloh (1999) measured PAR at mid-depth in a shallow ice-covered river in Vermont and found that the mean daily integrated irradiance was $3.3 \mathrm{mols} / \mathrm{m}^{2} /$ day during a late-winter ice-covered period. Their maximum observed PAR of $488 \mu \mathrm{mols} / \mathrm{m}^{2}$ is comparable to open-water wintertime values reported by Guasch et al. (1998) for rivers in Spain as well as to summertime measurements for shaded rivers.

\section{Permeability}

Dean (1976) and Beltaos and Dean (1981) used a constant head permeameter to determine the intrinsic permeability of frazil deposits. Dean reported a value of $1.53 \times 10^{-5} \mathrm{~cm}^{2}$, and Beltaos and Dean reported $1.56 \times 10^{-5} \pm 9.19 \times 10^{-7} \mathrm{~cm}^{2}$. These are comparable to the intrinsic permeability of a coarse sand or fine gravel deposit. However, the test method involved destructive sampling that may have affected their results. White (1991) used a borehole dilution method to determine permeability of a frazil ice accumulation in the laboratory. She reports an intrinsic permeability of $6.1 \pm$ $1.94 \times 10^{-7} \mathrm{~cm}^{2}$ (coefficient of variation $32 \%$ ) and hydraulic conductivity of $3.32 \pm 1.07 \times 10^{-2} \mathrm{~cm} / \mathrm{s}$ (coefficient of variation $32 \%$ ). These values correspond to a silty-to-clean sand deposit. Similar tests on frazil ice deposits in the Tanana River, Alaska, (White and Lawson 1992) resulted in the calculation of an intrinsic permeability of $2.75 \pm 1.76 \times$ $10^{-4} \mathrm{~cm}^{2}$ and hydraulic conductivity of $15.1 \pm 9.7$ $\mathrm{cm} / \mathrm{s}$, values analogous to a gravel deposit. The relatively high coefficient of variation $(69 \%)$ was attributed to large variation in the structure of the field deposits tested as indicated by borehole resistance logs.

\section{Ice piece size and distribution}

Little information regarding ice piece size and distribution in jams is available in the literature. A search of the CRREL Ice Jam Data Base (IJDB) in June 1999 identified some information on ice piece size in less than $0.2 \%$ of the records. It is clear from the available descriptions that damaging ice jams can occur when parent ice thickness ranges from very thin (about 6 in.) up to very thick $(4 \mathrm{ft})$. Brief estimates of floe size and distribution were given for two breakup jams and one freezeup jam. The only known quantitative size distribution is for brash ice (Fig. 15). The data were developed from a photograph taken on the St. Clair River in Feb-

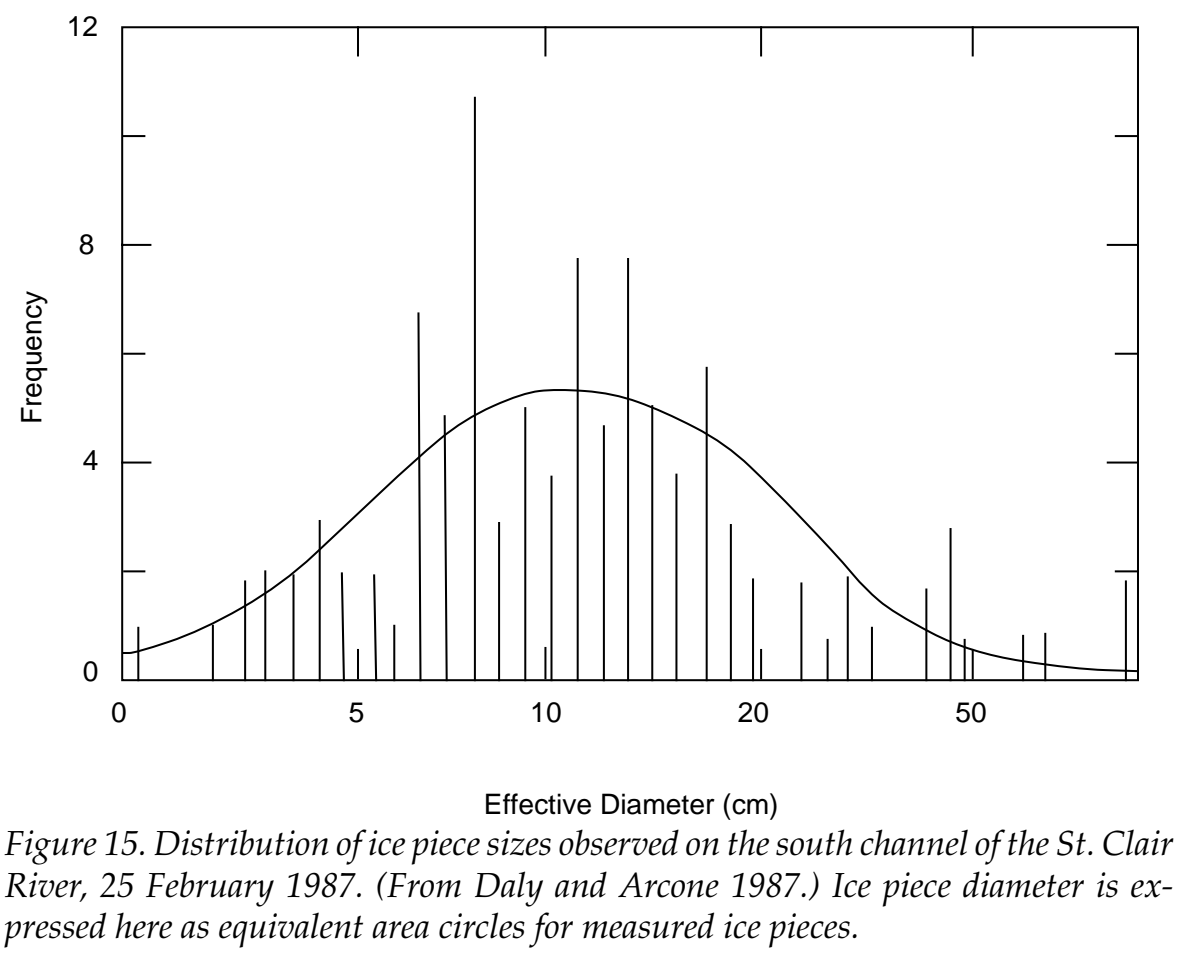


ruary 1987 (Daly and Arcone 1989). The wide variability in piece size given in this figure is also evident in qualitative descriptions contained in the IJDB of ice piece size provided for breakup jams. For example, White (1996): “The ice pieces near the toe appear to be thermally grown ice, four to eight inches thick, with occasional thicker pieces. The pieces are neither exceptionally large or small, and are in the range of two to six feet in diameter, with the mode closer to the smaller size." White (1993) and Tuthill (1993) also made observations of piece size and distribution for two ice jams that formed on the Black River in Coventry, Vermont, in 1993. The first jam formed in early January and was made of blocks generally 8 inches to 10 inches thick, ranging up to 18 inches. This jam froze in place and was followed by a later jam in March, for which ice pieces averaged 1 to 3 feet by $0.5 \mathrm{ft}$ thick. Lever et al. (1997) reported that ice piece size near the toe of breakup jams ranged from three to four times the ice thickness, similar to estimates by Wuebben and Stewart (1978).

\section{RELIABILITY CONSIDERATIONS}

In selecting an appropriate range of values for use in modeling, it is valuable to have some idea of the reliability of the properties described above. The coefficient of variation (COV) can be obtained from the distribution of known values:

$$
\operatorname{COV}=\frac{\sigma(x)}{E(x)}
$$

where $\sigma(x)$ is the standard deviation of the sample and $E(x)$ is its expected value, or mean.

Generally, sample sizes of the ice properties discussed above are too small to develop this information; the exception would probably be ice roughness. However, knowledge of the COV for various soil properties will provide an indication of the order of COV for similar ice properties. Harr (1987) summarizes the COVs for a number of soil and ice properties and provides references as well (see Table 5). He notes that a COV less than about $25 \%$ indicates a level of reliability acceptable in most engineering applications, while a COV greater than about $40 \%$ indicates unreliability.

Using the information in this table as a rough guide, we could consider that present knowledge of ice-influenced velocity, ice roughness, porosity of frazil ice deposits in the laboratory, and perhaps intrinsic permeability of frazil ice in the labora-
Table 5. Representative coefficients of variation (COV) based on data from Harr 1987 and some of the ice properties discussed in text.

\begin{tabular}{llc}
\multicolumn{1}{c}{ Property } & Material & $\begin{array}{c}\text { COV } \\
(\%)\end{array}$ \\
\hline Porosity $(p)$ & Soil & 10 \\
Specific gravity $(\gamma)$ & Soil & 2 \\
Internal angle of friction $(\phi)$ & Soil & 10 \\
Internal angle of friction for sand $(\phi)$ & Soil & 7 \\
Internal angle of friction for gravel $(\phi)$ & Soil & 12 \\
Cohesion $(c)$ & Soil & 40 \\
Thickness & Ice & 17 \\
Flexural strength & Ice & 20 \\
Crushing strength & Ice & 13 \\
Flow velocity & Ice & 33 \\
Ice roughness $\left(n_{\mathrm{i}}\right)$ & Ice & $35^{\mathrm{a}}$ \\
Porosity (frazil ice in laboratory) & Ice & $19 \mathrm{~b}$ \\
Intrinsic permeability of frazil & Ice & $32^{\mathrm{c}}$ \\
$\quad$ laboratory) & & \\
Intrinsic permeability of frazil $\quad$ Ifield) & Ice & $69^{\mathrm{d}}$ \\
Piece size & & \\
\hline
\end{tabular}

aCalculated from data presented in White and Daly (1997).

bCalculated from data presented in Andersson and Daly (1992). cWhite (1991).

dWhite and Lawson (1992).

eCalculated from data presented in Daly and Arcone (1989).

tory is reasonably reliable. It is clear that additional work is required before the intrinsic permeability of frazil ice in the field reaches an acceptable level of reliability. The same is true for the coefficient of internal strength $(\mu)$ and field values of porosity, whether for breakup jams or freezeup jams. Based solely on experience with soils, one would expect that values of porosity and friction angle for ice could be developed with some reliability, while it might be difficult to achieve the same level of reliability for ice cohesion. It is likely that further study could result in reasonably reliable estimates of frazil particle size; however, it is unlikely that the same can be developed for ice piece size.

\section{SUMMARY AND CONCLUSIONS}

An overview of ice jam hydraulics (juxtaposition, undercover deposition, and the formation of an ice jam from shoving and internal collapse) identified a group of variables important in hydraulic and physical processes, namely

- Ice cover roughness $\left(n_{\mathrm{i}}\right)$

- Cohesion $\left(C_{\mathrm{i}}\right)$ 
- Coefficient of internal strength $(\mu)$

- Angle of internal friction $(\phi)$

- Porosity $(p)$

- Shear force on the underside of the ice cover $(\tau)$

- Frazil particle diameter $(d)$ and fall velocity coefficient $\left(C_{\mathrm{i}}\right)$.

The ice-jam-related literature was searched for references to these variables, values of which were collected and reported in the present study. Based on these data, recommended values are shown in Table 6. At the present time, ice cover roughness, whether for frazil ice or breakup jams, is the only variable of those listed above that is known with any reliability. Much work remains to be done to determine reasonable values for the other variables, especially the coefficient of internal strength. Safety issues inherent in making field ob-

Table 6. Recommended values of hydraulic and physical properties affecting ice jams.

\begin{tabular}{lc}
\multicolumn{1}{c}{ Property } & Range of values \\
\hline Ice cover roughness $\left(n_{\mathrm{i}}\right)$ & \\
Freezeup ice cover & $0.010-0.060$ \\
Freezeup ice jam & $0.020-0.10$ \\
Breakup (thin ice) & $0.020-0.10$ \\
Breakup (thick ice) & $0.035-0.15$ \\
Cohesion $\left(C_{\mathrm{i}}\right)$ & \\
Freezeup ice jam & $960-1200 \mathrm{~Pa}$ \\
Breakup ice jam & $0-100 \mathrm{~Pa}$ \\
& \\
Coefficient of internal strength $(\mu)$ & $1.0-2.0$ \\
& \\
Angle of internal friction $(\phi)$ & $20^{\circ}-45^{\circ}$ \\
Frazil & $40^{\circ}-60^{\circ}$ \\
Rubble & \\
& \\
Porosity $(p)$ & 1.0 \\
Freezeup ice jam & \\
Frazil deposit & \\
Breakup ice jam & $0.35-0.45$ \\
& $0.35-0.6$ \\
Shear force on the underside of & \\
the ice cover $(\tau)$ & Calculated from \\
5-mm- to 1-cm-diameter particles & \\
Frazil particle diameter $(d)$ & \\
Frazil fall velocity coefficient $\left(C_{\mathrm{f}}\right)$ & \\
\hline & \\
& \\
& \\
& \\
& \\
& \\
& \\
&
\end{tabular}

servations have hindered the collection of field data for breakup jams. Advances in remote measurement technology may be invaluable in this regard.

Based on experience with soils, one would expect that values of porosity and internal angle of friction for ice could be developed with some reliability in the future, while it could be difficult to achieve the same level of reliability for ice cohesion. Reliable estimates of frazil particle diameter and fall velocity coefficient could be achieved with careful study. The primary obstacle in developing such estimates appears to be the difficulty in devising measurement methods for a material close to its melting point.

The literature review also provided information on other hydraulic and physical properties of ice jams that are of use to researchers and engineers interested in ice jam hydraulics. These are

- Anchor ice growth

- Jam erosion

- Ice cover velocity

- Coefficient of ice loss

- Thermal effects on ice jam

- Permeability

- Ice piece size and distribution.

Recent work in the area of anchor ice growth indicates that a Froude number greater than 0.2, and preferably larger than about 0.40 , is required for anchor ice growth. Permeability has also been the subject of recent attention, particularly in the case of grounded jams, where porous flow may be important in determining water levels. More work needs to be done in the area of jam erosion and thermal effects on jams, particularly for freezeup jams. Additional data on the coefficient of ice loss could be quite useful in determining jam volume.

\section{LITERATURE CITED}

Andersson, A., and S.F. Daly (1992) Laboratory investigation of trash rack freezeup by frazil ice. USA Cold Regions Research and Engineering Laboratory, CRREL Report 92-16.

Andres, D.D. (1980) The breakup process and the documentation of the 1978 ice jams on the Athabasca River at Fort McMurray. In Proceedings, Workshop on Hydraulic Resistance of River Ice, 23-24 September 1980, Burlington, Ontario, p. 143-161.

Andres, D.D. (1999) The effects of freezing on the 
stability of a juxtaposed ice cover. In Proceedings, 10th Workshop on River Ice, 9-11 June 1999, Winnipeg, Manitoba, p. 209-222.

Andres, D.D., and P.F. Doyle (1984) Analysis of breakup and ice jams on the Athabasca River at Fort McMurray, Alberta. Canadian Journal of Civil Engineering, 11: 444-458.

Ashton, G.D. (1974) Froude criterion for ice-block stability. Journal of Glaciology, 13(68): 307-313.

Ashton, G.D. (Ed.) (1986) River and Lake Ice Engineering. Littleton, Colorado: Water Resources Publications.

Atlas, R.M., and R. Bartha (1998) Microbial Ecology: Fundamentals and Applications. Menlo Park, California: Benjamin/Cummings Science Publishing.

Batchelor, G.K. (1967) An Introduction to Fluid Dynamics. Cambridge, England: Cambridge University Press.

Bear, J. (1972) Dynamics of Fluids in Porous Media. New York: Dover Press.

Belokon, P.N. (1938) On the coefficient of roughness of the ice cover. (In Russian.) Meteorology and Hydrology, No. 11-12.

Belokon, P.N. (1940) Engineering hydraulics of the flow under an ice cover. (In Russian.) Gosenergoizdat, M.

Beltaos, S. (1978) Field investigations of river ice jams. In Proceedings, IAHR Symposium on Ice Problems, 7-9 August 1978, Lulea, Sweden, vol. 2, p. 355371.

Beltaos, S. (1981) Ice freezeup and breakup in the Lower Thames River: 1979-80 observations. Environment Canada, Centre for Inland Waters, National Water Research Institute, unpublished report. Beltaos, S. (1982) River ice jams: Theory versus case studies. In Proceedings, Workshop on Hydraulics of Ice-Covered Rivers, 1-2 June 1982, Edmonton, Alberta, p. 319-330.

Beltaos, S. (1983) Ice freezeup and breakup in the Lower Thames River: 1980-81 observations. Environment Canada, Centre for Inland Waters, National Water Research Institute, unpublished report. Beltaos, S. (1988) Configuration and properties of a breakup jam. Canadian Journal of Civil Engineering, 15: 685-697.

Beltaos, S. (1993) Flow through breakup jams. In Proceedings, 11th Canadian Hydrotechnical Conference, 8-11 June 1993, Fredericton, New Brunswick, p. 643-652.

Beltaos, S. (Ed.) (1995) River Ice Jams. Highlands Ranch, Colorado: Water Resources Publications, LLC.

Beltaos, S. (1999) Flow through the voids of breakup ice jams. Canadian Journal of Civil Engineering, 26: 177-185.

Beltaos, S., and B. Burrell (1991) Case study of a grounded jam, Restigouche River, New Brunswick. In Proceedings, Northern Hydrology Symposium, July 1990, Saskatoon, Saskatchewan, National Hydrology Research Institute Symposium No. 6, p. 115.

Beltaos, S., and A.M. Dean, Jr. (1981) Field investigations of a hanging ice dam. In Proceedings, IAHR International Symposium on Ice, 27-31 July 1981, Quebec City, Canada, vol. 2, p. 475-488.

Beltaos, S., B. Burrell, and S. Ismail (1996) 1991 ice jamming along the Saint John River: A case study. Canadian Journal of Civil Engineering, 23: 381394.

Bolsenga, S.J. (1968) River ice jams: A literature review. Great Lakes Research Center Research Report RR 5-5, U.S. Army Corps of Engineers Lake Survey District, Detroit, Michigan.

Bolsenga, S.J., C.E. Herdendorf, and D.C. Norton (1991) Spectral transmittance of lake ice from 400 to $850 \mathrm{~nm}$. Hydrobiologia, 218: 15-25.

Bolsenga, S.J., M. Evans, H.A. Vanderploeg, and D.G. Norton (1996) PAR transmittance through thick, clear freshwater ice. Hydrobiologia, 330: 227230.

Brock, T.D., D.W. Smith, and M.T. Madigan (1984) Biology of Microorganisms. Englewood Cliffs, New Jersey: Prentice-Hall.

Brown, C.J.D., W.D. Clothier, and W. Alvord (1953) Observations on ice conditions and bottom organisms in the West Gallatin River, Montana. In Proceedings, Montana Academy of Sciences, vol. 13, p. 21-27.

Calkins, D.J. (1978) Physical measurements of river ice jams. Water Resources Research, 14(4): 693695.

Calkins, D.J. (1983) Ice jams in shallow rivers with floodplain flow. Canadian Journal of Civil Engineering, 10: 538-548.

Carey, K.L. (1966) Observed configuration and computed roughness of the underside of river ice, St. Croix River, Wisconsin. Geological Survey Research 1966, USGS Professional Paper 550-B, p. B192-B198.

Carey, K.L. (1967) The underside of river ice, St. Croix River, Wisconsin. Geological Survey Research 1967, USGS Professional Paper 575-C, p. C195-C199.

Chacho, E., D.E. Lawson, and B. Brockett (1986) Frazil ice pebbles: Frazil ice aggregates in the Tanana River near Fairbanks, Alaska. In Proceedings, International Association for Hydraulic Research 
Symposium on Ice, 18-22 August 1986, Iowa City, Iowa, vol. 3, p. 475-484.

Coutermarsh, B., and W.R. McGilvary (1991) Pressure distributions on an underturning ice floe. In Proceedings, 6th Workshop on the Hydraulics of River Ice, 23-25 October, Ottawa, Ontario, p. 143163.

Coutermarsh, B., and W.R. McGilvary (1993) Static analysis of floating ice block stability. Journal of Hydraulic Research, 31(2): 147-160.

Daly, S.F. (1984) Ice block stability. In Proceedings, ASCE Hydraulics Division Conference on Water for Resource Development, 14-17 August 1984, Coeur d'Alene, Idaho, p. 544-548.

Daly, S.F. (1994) Evolution of frazil ice in natural waterbodies. In International Association for Hydraulic Research Working Group on Thermal Regimes Report on Frazil Ice (S.F. Daly, Ed.). USA Cold Regions Research and Engineering Laboratory, Special Report 94-23.

Daly, S.F., and S.A. Arcone (1989) Airborne radar survey of a brash ice jam in the St. Clair River. USA Cold Regions Research and Engineering Laboratory, CRREL Report 89-2.

Daly, S.F., and K.D. Axelson (1990) Stability of floating and submerged blocks. Journal of Hydraulic Research, 28(6): 737-752.

Daly, S.F., A.M. Tuthill, J. Hayse, R. Valdez, B. Cowdell, and G. Burton (1997) Effect of daily fluctuations from Flaming Gorge Dam on the formation of ice covers on the Green River. Unpublished contract report prepared for the Western Area Power Administration, Golden, Colorado.

Daly, D.F., G. Brunner, S. Piper, M. Jensen, and A.M. Tuthill (1998) Modeling ice-covered rivers using HEC-RAS. In Proceedings, ASCE 9th International Conference on Cold Regions Engineering, 2730 September 1998, Duluth, Minnesota, p. 373-383.

Dean, A.M., Jr. (1976) A method for determining the permeability of frazil ice. USA Cold Regions Research and Engineering Laboratory, unpublished Technical Note.

Dean, A.M., Jr. (1986) Field techniques for obtaining engineering characteristics of frazil ice accumulations. In Proceedings, IAHR Ice Symposium 1986, 18-22 August, Iowa City, Iowa, vol. 3, p. 265278.

Ettema, R., and G.E. Urroz-Aguirre (1991) Friction and cohesion in ice rubble reviewed. In Proceedings, Sixth International Specialty Conference on Cold Regions Engineering, 26-28 February 1991, West Lebanon, New Hampshire, p. 316-325.

Ferrick, M.G., N.E. Yankielun, and D.F. Nelson (1996) A Doppler radar for continuous remote measurement of river ice velocity. Canadian Journal of Civil Engineering, 23: 408-417.

Fish, A.M., and Y.K. Zaretsky (1997) Ice strength as a function of hydrostatic temperature and pressure. USA Cold Regions Research and Engineering Laboratory, CRREL Report 97-6.

Flato, G., and R. Gerard (1986) Calculation of ice jam thickness profiles. In Proceedings, 4th Workshop on Hydraulics of River Ice, 19-20 June 1986, Montreal, vol. 1, p. C-3.1-C-3.25.

Gerard, R.L., and D.D. Andres (1982) Hydraulic roughness of freezeup ice accumulations: North Saskatchewan River through Edmonton. In Proceedings, Workshop on Hydraulics of Ice-Covered Rivers, 1-2 June 1982, Edmonton, Alberta, Canada, p. 6287.

Gogus, M., and J.-C. Tatinclaux (1981) Mean characteristics of asymmetric flows: Application to flow below ice jams. Canadian Journal of Civil Engineering, 8: 342-350.

Gosink, J.P., and T.E. Osterkamp (1983) Measurements and analyses of velocity profiles and frazil ice-crystal rise velocities during period of frazilice formation in rivers. Annals of Glaciology, 4: 7984.

Gray, D.M., and D.H. Male (1981) Handbook of Snow. Toronto: Pergamon Press.

Guasch, H., J. Armengal, E. Marti, and S. Sabater (1998) Diurnal variation in dissolved oxygen and carbon dioxide in two low-order streams. Water Research, (32)4: 1067-1074.

Hara, F., K. Takaharu, H. Kinoshita, H. Saeki, and H. Yamaguchi (1997) Fluid resistance of rubble field ice. In Proceedings, 9th Workshop on River Ice, 24-26 September 1997, Fredericton, New Brunswick, p. 101-110.

Harr, M.E. (1987) Reliability-Based Design in Civil Engineering. New York: McGraw-Hill, Inc.

Healy, D., F. Hicks, and S. Beltaos (1997) A comparison of the ICEJAM and RIVJAM ice jam profile models. In Proceedings, 9th Workshop on River Ice, 24-26 September 1997, Fredericton, New Brunswick, p. 269-288.

Hellman, J.-H. (1984) Basic investigations on mush ice. In Proceedings, IAHR Ice Symposium 1984, $27-$ 31 August 1984, Hamburg, Germany, vol. 3, p. 3755.

Hicks, F., K. MacKay, and S. Shabayek (1997) Modelling an ice jam release surge on the Saint John River, New Brunswick. In Proceedings, 9th Workshop on River Ice, 24-26 September 1997, Fredericton, New Brunswick, p. 303-314.

Hirayama, K., K. Terada, M. Sato, K. Hirayama, M. Sasamoto, and M. Yamazaki (1997) Field mea- 
surement of anchor and frazil ice. In Proceedings, 9th Workshop on River Ice, 24-26 September 1997, Fredericton, New Brunswick, p. 141-151.

Huokuna, M. (1988) The Finnish ice research project. In Proceedings, 5th Workshop on Hydraulics of River Ice/Ice Jams, 21-24 June 1988, Winnipeg, Manitoba, p. 15-41.

Ismail, S. (Ed.) (1997) Proceedings: 9th Workshop on River Ice, 24-26 September 1997, Fredericton, New Brunswick. Fredericton, New Brunswick: New Brunswick Power Corporation.

Jasek, M. (1997) Ice jam flood mechanisms on the Porcupine River at Old Crow, Yukon Territory. In Proceedings, 9th Workshop on River Ice, 24-26 September 1997, Fredericton, New Brunswick, p. 351-370. Kerr, D.J., H.T. Shen, and S.F. Daly (1997) Anchor ice formation and growth on gravel channel bed. In Proceedings, 9th Workshop on River Ice, 24-26 September 1997, Fredericton, New Brunswick, p. 153-171.

Kerr, D.J., H.T. Shen, and S.F. Daly (1998) Evolution and hydraulic resistance of anchor ice on gravel beds. In Proceedings, 14th International Symposium on Ice, 27-31 July 1998, Potsdam, New York, vol. 2.

Kivisild, H.R. (1959) Hanging ice dams. In Proceedings, 8th Congress of the IAHR, 24-25 August 1959, Montreal, vol. 2, paper 23-F, p. 1-30.

Knowles, W.L., and D.B. Hodgins (1980) Evaluation of ice jam roughness, Thames River, Ontario. In Proceedings, Workshop on Hydraulic Resistance of River Ice, 23-24 September 1980, Burlington, Ontario, p. 281-294.

Kondratyev, K. (1954) Radiant Energy of the Sun. Leningrad: Gidromet.

Korbaylo, B.W., and B.E. Shumilak (1999) A case study: Lower Churchill River water level enhancement weir project. In Proceedings, 10th Workshop on River Ice, 9-11 June 1999, Winnipeg, Manitoba, p. 135-149.

Larsen, P. (1975) Notes on the stability of floating ice blocks. In Proceedings, 3rd IAHR International Symposium on Ice Problems, 18-21 August 1975, Hanover, New Hampshire, p. 305-314.

Lever, J.H., and G.E. Gooch (1998) Model and field performance of a slope-blocked ice control structure. In Proceedings, 14th International Symposium on Ice, 27-31 July 1998, Potsdam, New York, vol. 2.

Lever, J.H., G.E. Gooch, A.M. Tuthill, and C.H. Clark (1997) Low-cost ice control structure. ASCE Journal of Cold Regions Engineering, 11(3): 198-220. Løset, S., and M. Sayed (1993) Proportional strain tests of fresh-water ice rubble. ASCE Journal of Cold Regions Engineering, 7(2): 44-61.

Lotter, G.K. (1932) Effect of ice formation on the design of diversion canals. (In Russian.) Bulletin, VNIIG, No. 7.

Lotter, G.K. (1941) Acad. N.N. Pavlovskiy's method for determining the coefficient of roughness of channels with ice cover. (In Russian.) Bulletin, VNIIG, No. 29.

Majewki, W., and M. Grzes (1986) Formation of ice cover on impounding reservoir and its influence on roughness coefficients and flow conditions. In Proceedings, IAHR Ice Symposium 1986, 1822 August, Iowa City, Iowa, vol. 1, p. 63-74.

McGilvary, W.R., and B. Coutermarsh (1992) Dynamic analysis of ice floe underturning stability. In Proceedings, IAHR Ice Symposium 1992, 15-19 June 1992, Banff, Alberta, vol. 1, p. 489-502.

McGilvary, W.R., A.M. Tuthill, and S.F. Daly (1995) Ice-affected flooding, Oahe Dam to Lake Sharpe, South Dakota, Ice Maps. Unpublished contract report prepared for the U.S. Army Corps of Engineers Omaha District, Omaha, Nebraska.

Michel, B. (1978) Ice Mechanics. Quebec: Les Presses de L'Université Laval.

Michel, B. (1980) Interpretation of Alberta ice jams data. Department of Civil Engineering, L'Université Laval, Report GCS-80-03.

Michel, B. (1984) Comparison of field data with theories on ice cover progression in large rivers. Canadian Journal of Civil Engineering, 11(4): 798-814. Michel, B., and M. Drouin (1981) Backwater curves under ice cover of the LaGrande River. (In French.) Canadian Journal of Civil Engineering, 8(3): 351-363. Nezhikhovskiy, R.A. (1964) Coefficients of roughness of bottom surface of slush-ice cover. Soviet Hydrology: Selected Papers, 2: 127-150.

Panov, B.P. (1960) Winter Regime of the Rivers of the USSR. (In Russian.) Leningrad: Leningrad State University Press.

Pariset, E., and R. Hausser (1961) Formation and evolution of ice covers on rivers. Transactions of the Engineering Institute of Canada, 5(1): 41-51.

Pariset, E., R. Hausser, and A. Gagnon (1966) Formation of ice covers and ice jams in rivers. ASCE Journal of the Hydraulic Division, 925(HY6): 1-24.

Petryk, S. (1995) Numerical modeling. In River Ice Jams. Highlands Ranch, Colorado: Water Resources Publications, LLC, p. 147-172.

Prodanovic, A. (1979) Model tests of ice rubble strength. In Proceedings, Fifth International Conference on Port and Ocean Engineering under Arctic Conditions, 13-18 August 1979, Trondheim, Norway, vol. 1, p. 89-105.

Prowse, T.D. (1986) Ice jam characteristics, LiardMackenzie rivers confluence. Canadian Journal of Civil Engineering, 13: 653-665. 
Prowse, T.D. (1988) Field determination of ice jam porosity. In Proceedings, IAHR Ice Symposium 1988, 23-27 August 1988, Sapporo, Japan, vol. 2, p. 316325.

Prowse, T.D. (1990) Heat and mass balance of an ablating ice jam. Canadian Journal of Civil Engineering, 17: 629-635.

Prowse, T.D., and P. Marsh (1989) Thermal budget of river ice covers during breakup. Canadian Journal of Civil Engineering, 16: 62-71.

Rivard, G., T. Kemp, and R.L. Gerard (1984) Documentation and analysis of the water level profile through an ice jam, Mackenzie River, Northwest Territories. In Proceedings, Workshop on the Hydraulics of River Ice, 20-21 June 1984, Fredericton, New Brunswick, p. 141-157.

Shen, H.T., and D.S. Wang (1992) Frazil jam evolution and cover load transport. In Proceedings, IAHR Ice Symposium 1992, 15-19 June 1992, Banff, Alberta, vol. 1, p. 418-429.

Shen, H.T., and D.S. Wang (1995) Under cover transport and accumulation of frazil granules. Journal of Hydraulic Engineering, 121(2): 184-195.

Sun, Z.-C., and H.T. Shen (1988) A field investigation of frazil ice jam in Yellow River. In Proceedings, 5th Workshop on the Hydraulics of River Ice/Ice Jams, June 1988, Winnipeg, Manitoba, p. 157-175.

Tatinclaux, J.-C., and M. Gogus (1981) Stability of floes below a floating cover. In Proceedings, IAHR International Symposium on Ice, 27-31 July 1981, Quebec City, Quebec, vol. 1, p. 298-311.

Timco, G.W., and A.M. Cornett (1999) Is $f$ a constant for broken ice rubble? In Proceedings, 10th Workshop on River Ice, 9-11 June 1999, Winnipeg, Manitoba, p. 318-331.

Tremblay, P.R., and D. Thibeault (1980) Analysis of hydraulic and ice conditions at Terrebonne in relation with spring and winter floods. In Proceedings of Workshop on Hydraulic Resistance of River Ice, 23-24 September 1980, Burlington, Ontario, p. 209226.

Tsang, G., and S. Beltaos (Ed.) (1980) Proceedings of Workshop on Hydraulic Resistance of River Ice. Burlington, Ontario: Environment Canada, Centre for Inland Waters, National Water Research Institute.

Tuthill, A.M. (1993) Unpublished trip report, USA Cold Regions Research and Engineering Laboratory, 31 March 1993.

Tuthill, A.M., and A.C. Mamone (1998) Structural ice control alternatives for middle Mississippi River. ASCE Journal of Cold Regions Engineering, 12(4): 202-220.

Tuthill, A.M., and K.D. White (1997) Breakup ice control structure for the Salmon River in Connecticut. In Proceedings, 9th Workshop on River Ice, 24-26 September 1997, Fredericton, New Brunswick, p. 125139.

Tuthill, A.M., J.L. Wuebben, S.F. Daly, and K.D. White (1996) Probability distributions for peak stages on rivers affected by ice jams. ASCE Journal of Cold Regions Engineering, 10(1): 36-57.

Tuthill, A.M., J.L. Wuebben, and J.J. Gagnon (1998) ICETHK User's Manual: Version 1. USA Cold Regions Research and Engineering Laboratory, Special Report 98-11.

U.S. Army Corps of Engineers (1982) Ice Engineering. Engineer Manual 1110-2-1612, U.S. Army Corps of Engineers, Washington, DC.

U.S. Army Corps of Engineers (1990, revised 1991) HEC-2 Water Surface Profiles User's Manual. Hydrologic Engineering Center Report CPD-2A. Hydrologic Engineering Center, Davis, California. U.S. Army Corps of Engineers (1995) UNET: Onedimensional unsteady flow through a full network of open channels, User's Manual. U.S. Army Corps of Engineers Hydrologic Engineering Center, Davis, California.

U.S. Army Corps of Engineers (1997) HEC-RAS River Analysis System, Hydraulic Reference Manual. U.S. Army Corps of Engineers Hydrologic Engineering Center, Davis, California.

U.S. Army Corps of Engineers (1999) Engineering and Design: Ice Engineering. Engineer Manual 1110-2-1612, U.S. Army Corps of Engineers, Washington, DC. Available at http:/www .usace.army.mil/ usace-docs/eng-manuals / em1110-2-1612/.

U.S. Army Engineer District, Omaha (USAED Omaha) (1979) Ice dusting of the Platte River, 1979. U.S. Army Engineer District, Omaha, Omaha, Nebraska.

Uzuner, M.S. (1975) The composite roughness of ice-covered streams. Journal of Hydraulic Research, 13(1): 79-102.

Uzuner, M.S., and J.F. Kennedy (1972) Stability of floating ice blocks. ASCE Journal of the Hydraulic Division, 95(HY12): 117-133.

Uzuner, M.S., and J.F. Kennedy (1974) Hydraulics and mechanics of river ice jams. Iowa Institute of Hydraulic Research Report No. 161, University of Iowa, Iowa City, Iowa.

Vincent, W.F., R. Rae, I. Laurion, C. Howard-Williams, and J.C. Priscu (1998) Transparency of Antarctic ice-covered lakes to solar UV radiation. Limnology and Oceanography, 43(4): 618-624.

Vogel, R.M., and M.J. Root (1981) The effect of floating ice jams on the magnitude and frequency 
of floods along the Missisquoi River in Northern Vermont. In Proceedings, IAHR International Symposium on Ice, 27-31 July 1981, Quebec City, Canada, vol. 1, p. 347-359.

Weiss, R.T., A. Prodanovic, and K.N. Wood (1981) Determination of ice rubble shear properties. In Proceedings, IAHR International Symposium on Ice, 27-31 July 1981, Quebec City, Canada, vol. 2, p. 860870.

White, K.D. (1991) Determining the intrinsic permeability of frazil ice. Part 1: Laboratory investigations. USA Cold Regions Research and Engineering Laboratory, CRREL Report 91-23.

White, K.D. (1993) Unpublished trip report, USA Cold Regions Research and Engineering Laboratory, 11 January 1993.

White, K.D. (1996) Unpublished trip report, USA Cold Regions Research and Engineering Laboratory, 5 February 1996.

White, K.D., and S.E. Acone (1998) Ice-cover thickening at river-reservoir confluences: A case study. In Proceedings, 9th International Conference on Cold Regions Engineering, 2730 September 1998, Duluth, Minnesota, p. 457-466.

White, K.D., and S.F. Daly (1997) The effects of uncertainty in ice roughness on equilibrium ice thickness and stage. In Proceedings, 9th Workshop on River Ice, 24-26 September 1997, Fredericton, New Brunswick, p. 89-99.

White, K.D., and D.E. Lawson (1992) Determining the intrinsic permeability of frazil ice. Part 2:
Field investigations. USA Cold Regions Research and Engineering Laboratory, CRREL Report 92-7. White, K.D., and R.A. Melloh (1999) Diurnal variation in dissolved oxygen measurements during late winter ice-covered period, Sleepers River, Vermont. In Proceedings, 10th International Conference on Cold Regions Engineering, 16-19 August 1999, Lincoln, New Hampshire, p. 550-560.

White, K.D., S.F. Daly, and J.J. Gagnon (1999) Simulating winter environments for aquatic life in the CRREL refrigerated flume. In Proceedings, 10th Workshop on River Ice, 9-11 June 1999, Winnipeg, Manitoba, p. 85-96.

Williams, G.P., and L.W. Gold (1963) Use of dust to advance the break-up of ice on lakes and rivers. In Proceedings, 1963 Annual Meeting, Eastern Snow Conference, 14-15 February 1963, Quebec City, Quebec, p. 31-56.

Wong, J., S. Beltaos, and B.G. Krishnappan (1985) Seepage flow through simulated grounded jam. Canadian Journal of Civil Engineering, 12: 926-929.

Wuebben, J.L., and D.M. Stewart (1978) Physical measurements of ice jams, 1976-1977 field season. USA Cold Regions Research and Engineering Laboratory, Special Report 78-3.

Zufelt, J.E. (1999) A simple test for the suitability of equilibrium thickness. In Proceedings, 10th Workshop on River Ice, 9-11 June 1999, Winnipeg, Manitoba, p. 1-14.

Zufelt, J.E., and R. Ettema (1997) Unsteady ice jam processes. USA Cold Regions Research and Engineering Laboratory, CRREL Report 97-7. 


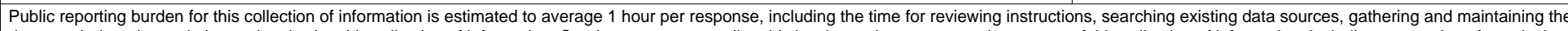

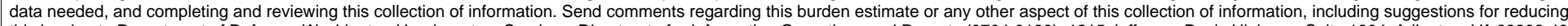

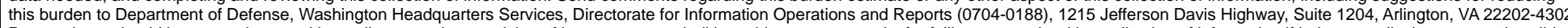

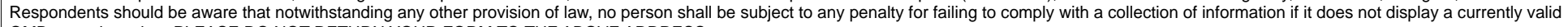
OMB control number. PLEASE DO NOT RETURN YOUR FORM TO THE ABOVE ADDRESS.
1. REPORT DATE $(D D-M M-Y Y)$
2. REPORT TYPE
3. DATES COVERED (From - To)
December 1999

4. TITLE AND SUBTITLE

Hydraulic and Physical Properties Affecting Ice Jams

5a. CONTRACT NUMBER

5b. GRANT NUMBER

5c. PROGRAM ELEMENT NUMBER

6. AUTHOR(S)

5d. PROJECT NUMBER

Kathleen D. White

5e. TASK NUMBER

5f. WORK UNIT NUMBER

33134

7. PERFORMING ORGANIZATION NAME(S) AND ADDRESS(ES)

Cold Regions Research and Engineering Laboratory

U.S. Army Engineer Research and Development Center

8. PERFORMING ORGANIZATION REPORT NUMBER

72 Lyme Road

CRREL Report 99-11

Hanover, New Hampshire 03755-1290

9. SPONSORING/MONITORING AGENCY NAME(S) AND ADDRESS(ES)

10. SPONSOR / MONITOR'S ACRONYM(S)

Office of the Chief of Engineers

Washington, D.C. 20314-1000

11. SPONSOR / MONITOR'S REPORT NUMBER(S)

\section{DISTRIBUTION / AVAILABILITY STATEMENT}

Approved for public release; distribution is unlimited.

Available from NTIS, Springfield, Virginia 22161.

13. SUPPLEMENTARY NOTES

14. ABSTRACT

Hydraulic modeling of ice jams can be used to predict jam location, stages, thickness, and other characteristics. Knowledge of the range and variability of hydraulics and physical properties affecting ice jams is necessary to reduce the uncertainty associated with such modeling. This report provides an overview of the processes involved in ice jam hydraulics and discusses properties important in these processes.

\begin{tabular}{|c|c|c|c|c|c|}
\hline 15. SUBJECT TERMS & \multicolumn{2}{|c|}{$\begin{array}{l}\text { Coefficient of internal friction } \\
\text { Frazil } \\
\text { Ice accumulation porosity }\end{array}$} & $\begin{array}{l}\text { Ice characteristics } \\
\text { Ice cohesion } \\
\text { Ice jam }\end{array}$ & \multicolumn{2}{|c|}{$\begin{array}{l}\text { Ice properties } \\
\text { Ice roughness } \\
\text { River ice }\end{array}$} \\
\hline \multicolumn{3}{|c|}{ 16. SECURITY CLASSIFICATION OF: } & \multirow{3}{*}{$\begin{array}{l}\text { 17. LIMITATION OF } \\
\text { OF ABSTRACT }\end{array}$} & \multirow{3}{*}{$\begin{array}{l}\text { 18. NUMBER } \\
\text { OF PAGES }\end{array}$} & 19a. NAME OF RESPONSIBLE PERSON \\
\hline a. REPORT & b. ABSTRACT & c. THIS PAGE & & & 19b. TELEPHONE NUMBER (include area code) \\
\hline Unclassified & Unclassified & Unclassified & & & \\
\hline
\end{tabular}

